\title{
Sistemas de IrRIGaÇÃo de CanaIS RadiculaReS: AvaliaçÃo Radiográfica, Histopatológica, Histomicrobiológica e Histoenzimológica, em Dentes de CÃes com Lesão Periapical
}

\author{
Dissertação apresentada à Faculdade de Odontologia de \\ Ribeirão Preto da Universidade de São Paulo, para obtenção \\ do título de Mestre em Ciências. Programa: Odontopediatria \\ Área de Concentração: Odontopediatria \\ Orientador: Prof. Dr. Paulo Nelson-Filho
}




\section{Autorização Para Reprodução}

Autorizo a reprodução e divulgação total ou parcial deste trabalho, por qualquer meio convencional ou eletrônico para fins de estudo e pesquisa, desde que citada a fonte.

Priscilla CoUtinho Romualdo

\section{Ficha CATALOGRÁFICA}

Romualdo, Priscilla Coutinho

Sistemas de irrigação de canais radiculares: Avaliação radiográfica, histopatológica, histomicrobiológica e histoenzimológica, em dentes de cães com lesão periapical. Ribeirão Preto, 2013.

97p. : il. ; $30 \mathrm{~cm}$

Dissertação de Mestrado apresentada à Faculdade de Odontologia de Ribeirão Preto/USP - Área de concentração: Odontopediatria.

Orientador: Prof. Dr. Paulo Nelson-Filho

1. Lesão periapical 2. Irrigação por pressão apical negativa; 3. Irrigação ultrassônica passiva; 4. Irrigação convencional por pressão positiva. 
Romualdo PC. Sistemas de Irrigação de Canais Radiculares: Avaliação Radiográfica, Histopatológica, Histomicrobiológica e Histoenzimológica, em Dentes de Cães com Lesão Periapical.

Dissertação apresentada à Faculdade de Odontologia de Ribeirão Preto da Universidade de São Paulo, para obtenção do título de Mestre em Ciências.

Programa: Odontopediatria

Área de Concentração: Odontopediatria

Data da defesa:

BANCA EXAMINADORA

$\operatorname{Prof}(\mathrm{a}) \cdot \operatorname{Dr}(\mathrm{a})$.

Julgamento: Assinatura:

$\operatorname{Prof}(\mathrm{a}) . \operatorname{Dr}(\mathrm{a})$ :

Julgamento: Assinatura:

$\operatorname{Prof}(\mathrm{a}) \cdot \operatorname{Dr}(\mathrm{a})$.

Julgamento: Assinatura: 



\section{Priscilla Coutinho Romualdo}

\section{Dados Curriculares}

Nascimento 03 de janeiro de $1989-$ Ipuã/SP.

Filiação Itamar Romualdo.

Rosângela Coutinho.

2007-2010 Curso de Graduação.

Faculdade de Odontologia de Ribeirão Preto - FORP/USP.

2009-2010 Iniciação Científica - Projeto de pesquisa intitulado "Utilização do localizador eletrônico foraminal iPex para odontometria - Estudo ex vivo em molares decíduos" (bolsa CNPq). Orientador: Prof. Dr. Paulo Nelson-Filho.

2011-2013 Curso de Especialização em Odontopediatria.

Associação Odontológica de Ribeirão Preto - AORP - Monografia intitulada "Eficácia in vivo do curativo de demora à base de hidróxido de cálcio, associado ou não ao digluconato de clorexidina, em dentes humanos decíduos com necrose pulpar e lesão periapical". Orientador: $\operatorname{Prof}^{\mathrm{a} .} \operatorname{Dr}^{\mathrm{a} .}$ Léa Assed Bezerra da Silva; Coorientador: Prof. Dr. Paulo Nelson-Filho.

2011-2013 Curso de Pós-Graduação em Odontopediatria, nível Mestrado.

Faculdade de Odontologia de Ribeirão Preto - FORP/USP - Dissertação intitulada "Sistemas de irrigação de canais radiculares: Avaliação radiográfica, histopatológica, histomicrobiológica e histoenzimológica, em dentes de cães com lesão periapical" (bolsa CAPES). Orientador: Prof. Dr. Paulo NelsonFilho. 



\section{DedicatórIA}

A Deus...

Pela graça da vida.

Por me guiar pelos melhores caminhos.

Pela presença e conforto constantes.

Por me presentear com familiares e amigos maravilhosos.

Pela oportunidade de mais uma conquista!

Aos meus amados pais... Rosângela Coutinho e Itamar Romualdo Por toda a confiança depositada em mim.

Pelo apoio e amor incondicionais. Por me proporcionarem condições para realizar meus sonhos. Por serem meus exemplos de vida e minha motivação!

Aos meus amados irmãos...

Carlos Henrique Romualdo, Flaveline C. Romualdo de Andrade

e Itamar Romualdo Jr.

Por todo apoio, amizade e incentivo.

Por acreditarem nos meus ideais.

Por todos os momentos maravilhosos que compartilhamos!

Aos meus amados sobrinhos...

Carolina Motarelli Romualdo, Carlos Henrique Romualdo Jr. e Matheus Romualdo de Andrade Pela imensa alegria que me proporcionam todos os finais de semana. Por serem minhas fontes de orgulho e inspiração!

A todos os meus familiares e amigos...

Que sempre torceram por mim,

e que também fazem parte dessa conquista!

"A verdadeira felicidade está na própria casa, entre as alegrias da família" (Léon Tolstoi) 



\section{Agradecimentos Especials}

\section{À minha família em Ribeirão Preto,}

\section{Janine Montenegro,}

Por ter me acolhido em um momento tão particular da minha vida.

Muito obrigada pela confiança e por me receber com tanto carinho.

\section{Katharina Morant Holanda de Oliveira,}

Por ter se tornado minha irmã e agora fazer parte da minha família. Obrigada pela paciência, pelo carinho, por todos os momentos divertidos e porter entrado na minha vida em um momento tão especial.

\section{Mariana Alencar Nemezio,}

Pelos inúmeros momentos de alegria e por toda a confiança.

Você é um exemplo de superação e determinação.

\section{Rachel Fernanda Matos,}

Por ter trazido mais alegria ao nosso apartamento.

Por tantos momentos especiais que dividimos em Ribeirão e em Ipuã.

Pela cumplicidade e confiança. 


\section{Agradecimentos Especials}

\section{Ao meu orientador Prof. Dr. Paulo Nelson-Filho,}

Por todos os ensinamentos, pela paciência e pela grande dedicação.

O senhor é minha fonte de inspiração e minha referência dentro da Odontologia.

Um exemplo de excelência profissional e de amor à profissão.

Professor, eu tenho muito orgulho de ser sua aluna.

Obrigada por todas as oportunidades, pela motivação constante

e por toda a confiança depositada em mim!

À Profa. Dra. Léa Assed Bezerra da Silva,

Por todas as oportunidades a mim oferecidas.

Pela grande contribuição na minha formação acadêmica.

Obrigada pelos ensinamentos e por toda a confiança!

\section{À Profa. Dra. Raquel Assed Bezerra da Silva,}

Por sempre estar presente na minha vida durante a graduação e o mestrado.

Muito obrigada por toda a ajuda, pelos momentos de alegria,

pelos ensinamentos transmitidos e pela disponibilidade.

Você é uma pessoa especial que transmite muita energia positiva,

sempre me incentivando!

À Profa. Dra. Andiara De Rossi,

Por toda a paciência, pelo apoio e pela disponibilidade.

Muito obrigada pelas palavras de incentivo e por todas as contribuições sempre tão pertinentes, neste e em outros trabalhos.

Desejo sempre estar ao seu lado para continuar compartilhando ensinamentos e momentos tão agradáveis! 


\section{AGRADECIMENTOS}

À Universidade de São Paulo, na pessoa do atual Reitor, Prof. Dr. João Grandino Rodas, e do Vice-Reitor, Prof. Dr. Hélio Nogueira da Cruz.

À Faculdade de Odontologia de Ribeirão Preto da Universidade de São Paulo, na pessoa do atual Diretor, Prof. Dr. Valdemar Mallet da Rocha Barros, e da Vice-Diretora, Profa. Dra. Léa Assed Bezerra da Silva.

À Coordenação do Curso de Pós-Graduação em Odontopediatria da Faculdade de Odontologia de Ribeirão Preto da Universidade de São Paulo, na pessoa da Coordenadora, Profa. Dra. Léa Assed Bezerra da Silva e da Vice-Coordenadora Profa. Dra. Raquel Assed Bezerra da Silva.

À CAPES (Coordenação de Aperfeiçoamento de Pessoal de Nivel Superior), pela bolsa concedida.

À FAPESP (Fundação de Amparo à Pesquisa do Estado de São Paulo), pelo auxílio à pesquisa concedido.

Aos professores da disciplina de Odontopediatria da Faculdade de Odontologia de Ribeirão Preto da Universidade de São Paulo:

Profa. Dra. Sada Assed, exemplo de dedicação profissional, pela grande colaboração deixada para a Odontopediatria, sendo uma fonte de inspiração para mim.

Profa. Dra. Aldevina Campos de Freitas, exemplo de dedicação à Odontopediatria. Obrigada pela simpatia e por todos os ensinamentos transmitidos.

Profa. Dra. Alexandra Mussolino de Queiroz, por todo apoio a mim oferecido desde a graduação e por todos os ensinamentos na clínica. Muito obrigada pelas palavras de conforto e pelos momentos de cumplicidade!

Profa. Dra. Maria Cristina Borsatto, por toda simpatia e pela convivência tão agradável. Obrigada por todos os ensinamentos e pelas palavras de incentivo e motivação.

Profa. Dra. Kranya Victoria Diaz Serrano, pelo carinho e atenção. Obrigada por todo o apoio, pelas palavras de conforto e pelos ensinamentos transmitidos durante as atividades clínicas.

Profa. Dra. Maria da Conceição Pereira Saraiva, professora da Disciplina de Epidemiologia, por toda a disponibilidade e paciência. Muito obrigada pelo apoio e incentivo desde a graduação. 
Nunca esquecerei todas as palavras de motivação para que eu continuasse na Odontologia e que me inspiraram a seguir a vida acadêmica. Obrigada, professora, por ter me mostrado uma luz em um momento tão difícil na minha vida. Espero que a senhora saiba a repercussão que seu apoio teve na minha vida profissional!

Aos professores da disciplina de Ortodontia da Faculdade de Odontologia de Ribeirão Preto da Universidade de São Paulo: Prof. Dr. Fábio Lourenço Romano, Prof. Dr. José Tarcísio Lima Ferreira, Prof. Dr. Adilson Thomazinho, Profa Dra. Mírian Aiko Nakane Matsumoto e Profa. Dra. Maria Bernadete Sasso Stuani, pela simpatia, pela convivência agradável no mesmo Departamento e por todos os ensinamentos transmitidos.

Aos Funcionários do Departamento de Clínica Infantil da Faculdade de Odontologia de Ribeirão Preto:

Marilia Pacífico Lucisano, pela disponibilidade e paciência durante todo o período de mestrado e também de iniciação científica. Ma, você se tornou uma amiga muito especial! Obrigada por todo o apoio, pelo carinho e pelos momentos de cumplicidade que dividimos! Você foi fundamental para o meu crescimento profissional e pessoal! Espero que nossa amizade se fortaleça cada dia mais!

Francisco Wanderlei Garcia de Paula e Silva e Carolina Paes Torres Mantovani, pela convivência agradável, pelos ensinamentos transmitidos, pela disponibilidade e pelo auxílio nas atividades clínicas.

Marco Antônio dos Santos, por toda a ajuda nas atividades laboratoriais deste trabalho, pela disponibilidade e pelos momentos de convivência agradável que compartilhamos.

Nilza Letícia Magalhães, pela grande simpatia, dedicação, apoio técnico e paciência! Obrigada pelos momentos de alegria e de cumplicidade! Você é especial!

Fátima Aparecida Jacinto Daniel e Tatiana Goudromihos pela ajuda nas atividades laboratoriais, pela disponibilidade e pelo bom-humor durante todo esse período de convivência.

Matheus Morelli Zanela e Filomena Leli Placciti, por toda a atenção e paciência, pela disponibilidade e, principalmente, pela convivência agradável. A dedicação e a ajuda de vocês foram de grande importância durante todo o curso de mestrado. 
Micheli Cristina Leite Rovanholo, por todo o apoio e pela imensurável paciência. Mi, você sempre me incentivou durante esses 2 anos de convivência. Muito obrigada pelas palavras de motivação e pelo carinho!

Aos funcionários da Clínica de Pacientes Especiąis, Benedita Viana Rodrigues, Fătima Aparecida Rizoli e Renata Aparecida Fernandes, por todo o apoio, pela dedicação e pela simpatia com que vocês tratam todos os alunos e pacientes.

Aos funcionários da Clínica 1: José Aparecido Neves do Nascimento, Vera do Nascimento Scandelai e Karina Dadalt Quaglio, pela simpatia, pela convivência agradável e pelo apoio nas atividades clínicas.

Aos colegas da Pós-Graduação em Odontopediatria da Faculdade de Odontologia de Ribeirão Preto da Universidade de São Paulo, Ana Caroline Fumes, Ana Zilda Nazar Bérgamo, Cristina Bueno Brandão, Daniela Silva Barroso de Oliveira, Danielly Cunha Araújo Ferreira, Daniele Lucca Longo, Denise de Souza Matos, Driely Barreiros de Oliveira, Fernanda Regina Ribeiro Santos, Gabriela Cristina Santin, Giselle de Ângelo Leite Carbonaro Guerreiro, Katharina Morant Holanda de Oliveira, Karina Grecca Pieroni, Késsia Suênia Fidélis de Mesquita, Letícia Andreotti Bignardi, Lidia Regina da Costa Hidalgo, Larissa Nogueira Soares Ribeiro, Marcela Cristina Damião Andrucioli, Mariana Alencar Nemezio, Marilia Rodrigues Moreira, Marina Fernandes de Sena, Marta Maria Martins Giamatei Contente, Maya Arnez, Rodrigo Teixeira Macri, Silvana Polizeli, Talita Pereira Prates e Talitha de Siqueira Mellara, pela troca de experiências, confidências e por todos os momentos de convivência agradáveis que compartilhamos! Ao lado de pessoas especiais a jornada é muito mais leve e alegre!

Às amigas de turma do mestrado, Ana Caroline Fumes, Daniele Lucca Longo, Denise de Souza Matos, Katharina Morant Holanda de Oliveira e Mariana Alencar Nemezio: vocês foram fundamentais na minha vida durante esses 2 anos! É imensurável meu carinho por vocês! Muito obrigada por tantos momentos de alegria, cumplicidade e confiança. Obrigada pelos abraços sinceros, pelas palavras de conforto, pelo apoio incondicional e por dividirem comigo esse momento tão especial para todas nós! 
Às amigas da graduação, Ana Flávia Maida, Ana Beatriz Souza, Andrea Sayuri, Larissa Ribeiro, Larissa Gabrielle, Mariana Crivelenti, Mariana Souza, Nathalia Giusti e Paula Ferreira, pelo apoio, pelo carinho e por todas as palavras de incentivo e motivação. Muito obrigada por todos os momentos de alegria que compartilhamos durante a graduação e por vocês continuarem fazendo parte da minha vida mesmo depois da formatura. É muito bom saber que posso contar sempre com vocês, apesar da distância. Vocês são muito especiąis! 
Ando devagar

Porque já tive pressa

Elevo esse sorriso

Porque já chorei demais

Hoje me sinto mais forte

Mais feliz quem sabe

só levo a certeza

De que muito pouco sei

Ou nada sei...

Conhecer as manhas

Eas manhãs

O sabor das massas

Edas maçãs

Épreciso amor

Pra poder pulsar

Epreciso paz pra poder sorrir

Épreciso a chuva para florir

Penso que cumprir a vida

Seja simplesmente

Compreender a marcha

Eir tocando em frente

Como um velho boiadeiro

Levando a boiada

Eu vou tocando os dias

Pela longa estrada eu vou

Estrada eu sou...

Almir Sater

(Tocando em Frente) 



\section{SUMÁRIO}

RESUMO

ABSTRACT

INTRODUÇÃO

PROPOSIÇÃO

MATERIAL E MÉTODOS

RESULTADOS

DISCUSSÃO

CONCLUSÃO 81

REFERÊNCIAS

ANEXO 



\section{Resumo}

Romualdo, PC. Sistemas de irrigação de canais radiculares: Avaliação radiográfica, histopatológica, histomicrobiológica e histoenzimológica, em dentes de cães com lesão periapical. Ribeirão Preto, 2013. 97p. Dissertação [mestrado]. Faculdade de Odontologia de Ribeirão Preto, Universidade de São Paulo.

O fundamento do sucesso da terapia endodôntica é baseado no controle da contaminação microbiana presente no sistema de canais radiculares. Com essa finalidade, novos sistemas de irrigação têm sido desenvolvidos, demonstrando maior eficácia e segurança, destacandose a irrigação por Pressão Apical Negativa (ANP) e a Irrigação Ultrassônica Passiva (PUI). O presente estudo in vivo teve como objetivo comparar a ANP e a PUI no reparo apical e periapical de dentes de cães com lesão periapical crônica, tendo como controle a irrigação convencional por Pressão Positiva (PP). Um total de 60 canais radiculares de pré-molares, com lesões periapicais experimentalmente induzidas, foram submetidos ao tratamento endodôntico em sessão única. Radiografias periapicais foram realizadas após a indução das lesões periapicais. Os dentes foram aleatoriamente divididos em 3 grupos: Grupo I Irrigação por Pressão Apical Negativa ( $n=20$ canais radiculares); Grupo II - Irrigação Ultrassônica Passiva ( $n=20$ canais radiculares) e Grupo III - Irrigação por Pressão Positiva (controle) ( $\mathrm{n}=20$ canais radiculares). Após 180 dias, os animais foram eutanasiados, as peças removidas e submetidas ao processamento histotécnico para a análise histopatológica morfológica e morfométrica, em cortes corados com HE, sob microscopia convencional e de fluorescência. A análise radiográfica do tamanho das lesões periapicais foi realizada através da comparação das medidas das áreas das lesões antes e 180 dias após o tratamento endodôntico. Também foi realizada a histoenzimologia para a Fosfatase Ácida Resistente ao Tartarato (TRAP), para a marcação de osteoclastos, e a coloração de Brown e Brenn, para avaliar a presença de bactérias e sua localização. Os resultados obtidos foram submetidos à análise estatística por meio do teste de Kruskal-Wallis. O nível de significância adotado foi de 5\%. Observou-se que não houve diferença estatisticamente significante entre os grupos com relação à resposta radiográfica $(p=0,91)$. Na comparação dos parâmetros histopatológicos, o grupo I apresentou resultados mais homogêneos. Houve diferença estatisticamente significante entre os grupos I e III, com infiltrado inflamatório mais suave no grupo I $(p=0,02)$, enquanto o grupo II foi semelhante aos grupos I e III. Na comparação das variáveis numéricas (morfometria em microscopia de fluorescência e TRAP), não foi possível observar diferença significativa entre os grupos $(p>0,05)$. Os resultados deste estudo in vivo demonstraram que a irrigação por ANP resultou em resposta inflamatória mais suave, em comparação ao grupo controle, porém, semelhante à PUI. Nos demais aspectos, a resposta dos tecidos apicais e periapicais, após irrigação por ANP ou PUI, foi semelhante à irrigação convencional por PP.

Palavras-chave: Lesão periapical, Irrigação por pressão apical negativa, Irrigação ultrassônica passiva, Irrigação convencional por pressão positiva. 

Abstract

Romualdo, PC. Root canal irrigation systems: radiographic, histopathological, histomicrobiological and histoenzymological evaluation in dogs' teeth with apical periodontitis. Ribeirão Preto, 2013. 97p. Dissertação [mestrado]. Faculdade de Odontologia de Ribeirão Preto, Universidade de São Paulo.

A successful endodontic therapy relies on the control of microbial contamination of the root canal system. For this purpose, new irrigation systems with greater efficacy and safety have been developed, standing out the apical negative pressure (ANP) and the passive ultrasonic (PUI) irrigation systems. The aim of this in vivo study was to compare apical positive pressure irrigation (PP - conventional irrigation), ANP and PUI in the apical and periapical repair of dog's teeth with chronic periapical lesion. Sixty root canals of premolars with experimentally induced periapical lesions were subjected to a single-session endodontic treatment. Periapical radiographs were taken after inducing the periapical lesions. The teeth were randomly assigned to three groups: Group I: ANP with EndoVac ( $n=20$ root canals); Group II: PUI ( $\mathrm{n}=20$ root canals) and Group III: apical positive pressure irrigation (PP conventional irrigation - control) ( $n=20$ root canals). After 180 days, the animals were euthanized, and the anatomic pieces were removed and subjected to histotechnical processing for histopathological, morphological and morphometric analyses of HE-stained sections under conventional and fluorescence microscopy. The radiographic analysis of the size of periapical lesions was performed by measuring the lesions before and 180 days after the endodontic treatment. Tartrate-resistant acid phosphatase (TRAP) histoenzymology for identification of osteoclasts and Brown and Brenn staining for identification and localization of bacteria were also performed. Data were analyzed statistically by the Kruskal-Wallis test a significance level of $5 \%$. There were no statistically significant differences among the groups regarding the radiographic response $(p=0.91)$. In the comparison of histopathological parameters, Group I presented more homogeneous results. There was a statistically significant difference between Groups I and III, with milder infiltrate inflammatory in Group I $(p=0.02)$. Group II was similar to Groups I and III. Comparing the numerical variables (morphometric analysis under fluorescence microscopy and TRAP), no statistically significant difference could be found among the groups ( $p>0.05)$. The results of this in vivo study revealed that ANP caused milder inflammatory response than PP (control group), but similar to PUI. In the other aspects, the response of apical and periapical to ANP and PUI was similar to tissue response to PP.

Key words: Periapical lesion, apical negative pressure irrigation, passive ultrasonic irrigation, apical positive pressure irrigation (conventional irrigation). 

Introdução 



\section{INTRODUÇÃO}

O fundamento do sucesso após tratamento endodôntico de dentes portadores de necrose pulpar e lesão periapical é baseado na completa remoção de material necrótico e de micro-organismos e seus subprodutos, presentes no sistema de canais radiculares (Schilder, 1974; Leonardo et al., 1993; Malentacca et al., 2012). Isso ocorre uma vez que os metabólitos tóxicos e subprodutos liberados pelos microorganismos remanescentes difundem-se em direção aos tecidos apicais, ocasionando uma resposta inflamatória, acompanhada de reabsorção dos tecidos mineralizados (Kakehashi et al., 1965; Moller et al., 1981; Love e Jenkinson, 2002; Shekhar e Shashikala, 2013). Como demonstrado por Sjogren et al. (1997), em um estudo clínico, o sucesso do tratamento endodôntico é diretamente relacionado à presença ou ausência de micro-organismos previamente à obturação do canal radicular.

Sabe-se que o preparo biomecânico dos canais radiculares, conjuntamente com o uso da medicação intracanal e com a obturação, tem sido empregado com o objetivo de favorecer o controle dos níveis de micro-organismos viáveis no sistema de canais radiculares, nos dentes portadores de necrose pulpar e lesão periapical crônica visível radiograficamente (Sjogren et al., 1997; Nair et al., 2005; Leonardo, 2005; Ito et al., 2011; Vera et al., 2012). No entanto, sabe-se que, independentemente da técnica de instrumentação utilizada, grande parte da superfície das paredes dos canais pode apresentar, ainda, contaminação microbiana (Sjogren et al., 1997; Peters et al., 2002; Siqueira et al., 2007; Adcock et al., 2011; Rôças e Siqueira, 2012). Admite-se, também, que em dentes infectados e com lesão periapical crônica, as bactérias podem persistir nas ramificações do canal radicular principal, nos túbulos dentinários expostos, nas lacunas do cemento celular e no forame apical, ou seja, fora da luz do canal radicular principal (Leonardo et al., 2002; Rocha et al., 2008; Wang et al., 2012), que são áreas inacessíveis ao preparo biomecânico. Assim, as técnicas de instrumentação rotineiramente utilizadas durante o tratamento endodôntico possivelmente não eliminam completamente a infecção microbiana e particularmente as bactérias mais resistentes podem sobreviver e manter o processo infeccioso e inflamatório nos tecidos periapicais (Tronstad et al., 1987). 
A técnica de tratamento endodôntico preconizada por vários autores para dentes decíduos e permanentes portadores de lesão periapical inclui a realização de um curativo de demora, geralmente à base de hidróxido de cálcio. O sucesso histopatológico obtido com esse medicamento é superior ao tratamento efetuado em sessão única (Katebzadeh et al., 1999; Holland et al., 2003; Leonardo et al., 2006; Silveira et al., 2007; Paula-Silva et al., 2009; Vera et al., 2012). Porém, alguns estudos apontam que não há diferenças entre o tratamento efetuado em sessão única ou dupla (Sathorn et al., 2005; Naito, 2008; Sathorn et al., 2008; Balto, 2009; Prashanth et al., 2011; Paredes-Vieyra e Enriquez, 2012), o que têm impulsionado os pesquisadores a buscarem novas técnicas que possam eliminar a necessidade da realização do curativo de demora, incluindo variações na forma de se efetuar a irrigação/aspiração durante o preparo biomecânico.

Assim, o aperfeiçoamento dos protocolos de irrigação atualmente disponíveis para a limpeza das regiões inacessíveis dos canais radiculares e das superfícies não instrumentadas é de extrema importância (Gomes-Filho et al., 2008; Munoz e Camacho-Cuadra, 2012).

Sabe-se que a capacidade de uma solução irrigadora ser distribuída dentro de um sistema fechado de canais é dependente da anatomia do canal radicular, do tamanho e da conicidade da instrumentação mecânica e do sistema de irrigação utilizado (De Gregorio et al., 2009; 2010), sendo o terço apical a área mais crítica, devido à anatomia complexa dessa região (Morfis et al., 1994; Morroquin et al., 2004; Meder-Cowherd et al., 2011).

Quando utiliza-se a irrigação convencional por Pressão Positiva (PP), a eficácia é diretamente dependente da profundidade de penetração da agulha e do volume da solução utilizada (Abou-Rass e Piccinino, 1982; Chow, 1983). Entretanto, embora a eficiência aumente ao se introduzir a agulha mais próximo ao forame apical, a possibilidade de extrusão da solução além do forame é elevada, podendo resultar em danos severos aos tecidos periapicais e em dor pós-operatória, além de retardar o processo de reparo (Hulsmann e Hahn, 2000; Mehdipour et al., 2007; Gondim et al., 2010).

Desta forma, com a finalidade de superar estas limitações críticas, novos sistemas de irrigação têm sido desenvolvidos. Dentre esses novos sistemas, destacam-se a Irrigação Ultrassônica Passiva e a Irrigação por Pressão Apical 
Negativa (van der Sluis et al., 2005; Burleson et al., 2007; Haapasalo et al. 2010, Cohenca et al., 2013; Spoorthy et al., 2013).

Os dispositivos ultrassônicos foram introduzidos na Endodontia por Richman, em 1957. As pontas ultrassônicas têm o potencial de preparar e desbridar o sistema de canais radiculares, oscilando em frequências ultrassônicas de 25 a $30 \mathrm{kHz}$, as quais estão além do limite da audição humana (Walmsley, 1987; van der Sluis et al., 2007). Os sistemas de irrigação ultrassônicos podem proporcionar maior eficácia na limpeza e desinfecção dos canais radiculares e do forame apical (Goodman et al., 1985; Metzler e Montgomery, 1989; Lee et al., 2004; Burleson et al. 2007; BlankGonçalves et al., 2011), atingindo áreas não acessíveis à instrumentação (Lee et al., 2004; van der Sluis et al., 2005; Al-Jadaa et al., 2009; De Gregorio et al., 2010) e reduzindo o número de micro-organismos, em comparação à irrigação convencional (Spoleti et al., 2003).

A literatura descreve dois tipos de irrigação ultrassônica. Um tipo consiste na Irrigação Ultrassônica Passiva (PUI) e o outro em uma combinação simultânea de instrumentação e irrigação ultrassônica. No entanto, devido à dificuldade do controle do corte da dentina e, consequentemente, da forma final do canal radicular, essa combinação simultânea não é considerada uma alternativa à instrumentação convencional manual (Abbott et al., 1991; van der Sluis et al., 2005; 2007), sendo a PUI mais indicada (Munley e Goodell, 2007; Mozo et al., 2012).

A PUI é uma abordagem complementar que tem sido recomendada para a desinfecção após a instrumentação, consistindo na ativação ultrassônica de um irrigante, geralmente o hipoclorito de sódio. O termo PUI foi usado pela primeira vez por Weller et al., em 1980, para descrever a irrigação ultrassônica sem a instrumentação simultânea. O termo "passiva" refere-se à ação não cortante do instrumento ultrassônico ativado, utilizado no procedimento. A PUI inclui o uso de soluções irrigadoras por meio de seringas, com a ativação ultrassônica subsequente, ou a liberação contínua do irrigante por meio de peça de mão ultrassônica (Cameron, 1988; Gu et al., 2009).

Van der Sluis et al. (2007), após revisão da literatura, concluíram que a PUI pode ser um tratamento adjuvante na limpeza dos canais radiculares com maior eficácia, em comparação à irrigação convencional. No entanto, seu efeito potencial no favorecimento da resposta reparadora dos tecidos apicais e periapicais de dentes com lesão periapical não foi, ainda, avaliado. 
Recentemente, foi introduzido um protocolo alternativo de irrigação do sistema de canais radiculares por meio de Pressão Apical Negativa (EndoVac ${ }^{\circledR}$; Discus Dental, Culver City, CA) que, segundo a literatura específica, apresenta maior potencial de limpeza, segurança e grande capacidade de eliminação do conteúdo microbiano dos canais radiculares (Nielsen e Baumgartner, 2007; Desai e Himel, 2009; Cohenca et al., 2010; 2013). Esse protocolo destaca-se pela característica de promover menor extrusão de solução irrigadora para os tecidos periapicais (Fukumoto et al., 2006; Desai e Himel, 2009; Mitchell et al., 2011), além disso, é mais efetivo na remoção de debris e na liberação de solução irrigadora no comprimento de trabalho, em comparação à PP (Shin et al., 2010; Munoz e Camacho-Cuadra, 2012; Ribeiro et al., 2012).

O sistema $E n d o V a c^{\circledR}$ é um dispositivo de Irrigação por Pressão Apical Negativa (ANP), empregado em um protocolo que engloba duas fases: a macroirrigação e a microirrigação. A ponta, que promove a irrigação/aspiração, é adaptada a uma seringa de irrigação e à alta velocidade de sucção do equipo odontológico. Um pequeno tubo prende tanto a macro como a microcânula para a sucção. A ponta de irrigação/aspiração libera a solução irrigadora na câmara pulpar e remove o excesso para prevenir o sobrefluxo. A macrocânula é plástica e apresenta uma abertura final medida de acordo com os padrões da International Standards Organization (ISO) no calibre de 55 (ou 0,55mm) com um taper .02, a qual atua promovendo a sucção do fluido. A microcânula, de aço inoxidável e com a extremidade fechada, apresenta doze pequenos orifícios posicionados lateralmente, distribuídos em quatro fileiras de três orifícios e calibre de acordo com os padrões ISO de 32 (ou 0,32mm) e, do mesmo modo que a macrocânula, promove sucção do fluido. Como estas cânulas são colocadas no interior dos canais radiculares, a diferença de pressão no interior de cada uma promove a sucção do excesso de solução irrigadora, havendo renovação da solução irrigadora com um novo suprimento da mesma. A solução irrigadora difunde-se pelo canal radicular até a ponta da cânula, circulando dentro e fora desta por meio da mangueira de sucção. Este sistema permite a utilização de um volume maior de solução irrigadora, quando comparado ao sistema de irrigação convencional (seringa/cânula), no mesmo intervalo de tempo (Nielsen e Baumgartner, 2007).

O sistema $\mathrm{EndoVac}^{\circledR}$ vem sendo considerado um protocolo de desinfecção promissor para o controle de micro-organismos (Cohenca et al., 2010; 2013), 
favorecendo a ocorrência do processo de reparo, em dentes com rizogênese incompleta portadores de lesão periapical (Silva et al., 2010). Ressalta-se que, na área médica, a pressão negativa tem sido muito estudada no tratamento de feridas crônicas, pois esse método reduz a carga microbiana e evita a formação de biofilme (Bradley e Cunningham, 2013).

Embora a ANP tenha evidenciado condições favoráveis para a ocorrência do processo de reparo periapical, em estudo histopatológico de dentes de cães com rizogênese incompleta (Silva et al., 2010) não há, ainda, estudos publicados avaliando a resposta microscópica frente ao uso dessa técnica em dentes com ápice completo e presença de lesão periapical. Considerando que nos dentes portadores de necrose pulpar e lesão periapical crônica há a presença de infecção intra e extrarradicular, com predomínio de micro-organismos anaeróbios, especialmente no terço apical do canal radicular (Assed et al., 1996; Siqueira et al., 2004; Ito et al., 2011), a ação desses novos sistemas de irrigação poderia favorecer a resposta dos tecidos apicais e periapicais.

Tradicionalmente, a avaliação do reparo ou da persistência da lesão periapical pós-tratamento endodôntico é realizada por meio de testes clínicos e exame radiográfico ( $\mathrm{Ng}$ et al., 2007). Embora o método radiográfico convencional seja o mais utilizado na prática clínica, o mesmo subestima o tamanho da lesão periapical pós-tratamento (Paula-Silva et al., 2009). Além disso, em muitos casos, a lesão periapical pode persistir por vários anos, após o término tratamento endodôntico, mesmo sem a presença de sinais e sintomas clínicos ou sinais radiográficos (Katebzadeh et al., 1999). Por outro lado, estudos in vivo utilizando avaliações microscópicas têm sido considerados "padrões-ouro" para a determinação da presença ou não de inflamação e reabsorção óssea na região periapical (Leonardo, 2005; Paula-Silva et al., 2009; Teixeira et al., 2011).

Pelo exposto, verifica-se a necessidade da realização de estudos que avaliem a resposta tecidual apical e periapical, após o tratamento endodôntico de dentes com lesão periapical crônica, tendo como foco o protocolo de irrigação utilizado. 

Proposição 



\section{Proposição}

O presente estudo in vivo teve como objetivo comparar a resposta tecidual após irrigação convencional por Pressão Positiva (PP - controle), irrigação por Pressão Apical Negativa (ANP) e Irrigação Ultrassônica Passiva (PUI), em dentes de cães com lesão periapical crônica induzida, por meio de avaliação radiográfica, histopatológica, histomicrobiológica e histoenzimológica. 

Material e Métodos 



\section{Material e Métodos}

O projeto foi, inicialmente, submetido à apreciação pelo Comitê de Ética em Pesquisa no Uso de Animais do Campus da Universidade de São Paulo, tendo sido aprovado (Protocolo 014/2012 - Anexo A). Os procedimentos experimentais foram realizados de acordo com as orientações e com o regulamento do referido Comitê e com base no protocolo recomendado pela International Organization for Standardization (ISO standard 7405:1997).

Um total de 30 dentes (60 canais radiculares) de segundos e terceiros prémolares superiores e segundos, terceiros e quartos pré-molares inferiores, de 3 cães beagles, com 12 meses de idade, foram selecionados para esse estudo e divididos em 3 grupos (Tabela 1).

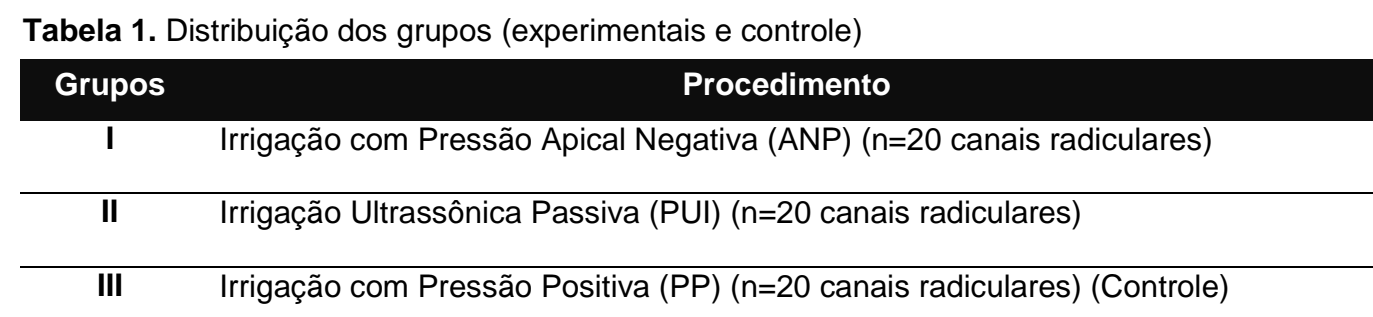

Os animais foram pré-anestesiados por meio de injeção endovenosa de Neozine (Farmácia Aventis Ltda., São Paulo, SP, Brasil; 1mg por quilo de peso corpóreo), 15 minutos antes do procedimento operatório quando, então, foram anestesiados com injeção endovenosa de cloridrato de tiletamina / cloridrato de zolazepam (Zoletil 50; Virbac do Brasil Ind. e Com Ltda., São Paulo, SP, Brasil; $0,1 \mathrm{~mL} / \mathrm{kg}$ de peso corpóreo) para facilitar a passagem do tubo endotraqueal. A anestesia inalatória com isoflurano (Abbott Laboratories Ltd., St. Laurent, Quebec, Canada) foi efetuada usando o aparelho Takaoka KT-20 (Takaoka Indústria e Comércio Ltda, São Paulo, SP, Brasil). Durante todo o procedimento operatório, os animais foram mantidos com solução salina isotônica ( $\mathrm{NaCl}$ 0,9\% - Glicolabor Indústria Farmacêutica Ltda., Ribeirão Preto, SP, Brasil).

Todos os dentes foram examinados radiograficamente antes do início do estudo e submetidos à abertura coronária com pontas esféricas diamantadas, complementada com pontas diamantadas cônicas (KG Sorensen, São Paulo, SP, Brasil), sob refrigeração abundante. Após a remoção do tecido pulpar, os canais 
radiculares foram deixados expostos à cavidade bucal durante 7 dias, para possibilitar a contaminação microbiana. Após esse período, a câmara pulpar foi fechada com cimento de óxido de zinco e eugenol (S.S. White, Rio de Janeiro, RJ, Brasil), para promover a indução das lesões periapicais, conforme preconizado por Leonardo et al. (1993).

Radiografias padronizadas foram realizadas quinzenalmente com o objetivo de acompanhar o desenvolvimento da lesão periapical. Após 45 dias do selamento coronário, foram constatadas imagens radiolúcidas sugestivas de lesões periapicais experimentalmente induzidas. Todo o protocolo experimental foi executado em quadrantes alternados e de modo randomizado.

Após a indução das lesões periapicais, os dentes foram isolados com dique de borracha e o campo operatório submetido à antissepsia com peróxido de hidrogênio a $30 \%$, até não haver mais borbulhamento do peróxido, seguido do uso de tintura de iodo. Após secagem, a restauração temporária foi removida.

O comprimento de trabalho (CT) foi estabelecido $1 \mathrm{~mm}$ aquém do ápice radiográfico e confirmado por meio da utilização de localizador eletrônico foraminal (Root ZXII, J Morita Corp. Kyoto, Japan). Em seguida, foi realizada a instrumentação até o CT com limas de níquel-titânio do Sistema Protaper Universal (Dentsply/Maillefer, Oklahoma, USA), acionadas pelo motor X-Smart (Dentsply/Maillefer, Oklahoma, USA), até a lima F3 ou F4, de acordo com o calibre do canal radicular. A irrigação do sistema de canais radiculares foi efetuada com 2,0 $\mathrm{mL}$ de hipoclorito de sódio $(\mathrm{NaOCl})$ a $5,25 \%$ a cada troca de instrumento.

Durante a instrumentação, cada canal radicular foi irrigado de acordo com o protocolo estabelecido para cada grupo:

Grupo I - neste grupo foi utilizada a irrigação com ANP (sistema EndoVac ${ }^{\circledR}$; Discus Dental, Culver City, CA, USA), durante toda a instrumentação, englobando as duas fases principais (macro e microirrigação), de acordo com as recomendações do fabricante. A sequência de irrigação final foi realizada com 30 segundos de $\mathrm{NaOCl}$ a $5,25 \%$ (macroirrigação), 30 segundos de EDTA a 17\% (microirrigação) e 30 segundos de $\mathrm{NaOCl}$ a $5,25 \%$ (microirrigação).

Grupo II - durante a instrumentação, a irrigação foi realizada utilizando agulha convencional de calibre 30G (Max-i-Probe; Dentsply / Tulsa Dental, York, PA). A sequência de irrigação final foi realizada com 30 segundos de $\mathrm{NaOCl}$ a $5,25 \%$ seguida pela PUI por 20 segundos, 30 segundos de EDTA a 17\% seguida pela PUI 
por 20 segundos e 30 segundos de $\mathrm{NaOCl}$ a 5,25\% também seguida pela PUI por 20 segundos. A PUI foi efetuada por meio de pontas especificamente projetadas Irrisafe (Satelec, Acteon Group Merignac cedex, França), montadas em uma unidade ultrassônica P5 Neutron XS (Satelec, Acteon Group Merignac, França), na configuração de potência 10, como recomendado por Jiang et al. (2011).

Grupo III (controle) - os canais radiculares foram irrigados por meio de uma agulha convencional de calibre 30G (Max-i-Probe; Dentsply / Tulsa Dental, York, PA) e pressão positiva (PP - irrigação convencional). A irrigação final foi realizada com 30 segundos de $\mathrm{NaOCl}$ a 5,25\%, 30 segundos de EDTA a 17\% e 30 segundos de $\mathrm{NaOCl}$ a $5,25 \%$.

Os canais radiculares foram então secos com pontas de papel absorvente esterilizadas, seguido da obturação com cones de guta-percha e cimento AH-Plus (Dentsply - De Trey, Konstanz, Germany), utilizando a técnica de condensação lateral. Radiografias periapicais foram tomadas para avaliar a qualidade da obturação final e as entradas dos canais foram seladas com MTA ProRoot (Dentsply Tulsa Dental, Johnson City, TN). Em seguida, foi efetuada a restauração dos elementos dentais com amálgama de prata (Sybraloy; Kerr Corporation, Orange, CA).

Decorridos 180 dias, os animais foram submetidos à eutanásia. As maxilas e mandíbulas foram dissecadas e seccionadas para se obter raízes individuais, as quais foram submetidas ao processamento histotécnico. Ao final do processamento, foram obtidas secções longitudinais de $5 \mu \mathrm{m}$ de espessura, as quais foram coradas com hematoxilina e eosina (HE) para avaliação microscópica.

Durante todo o experimento e período pós-operatório, os cães foram monitorados diariamente, para verificação da possível ocorrência de dor relacionada com os procedimentos odontológicos.

A Figura 1 apresenta o fluxograma da metodologia empregada. 


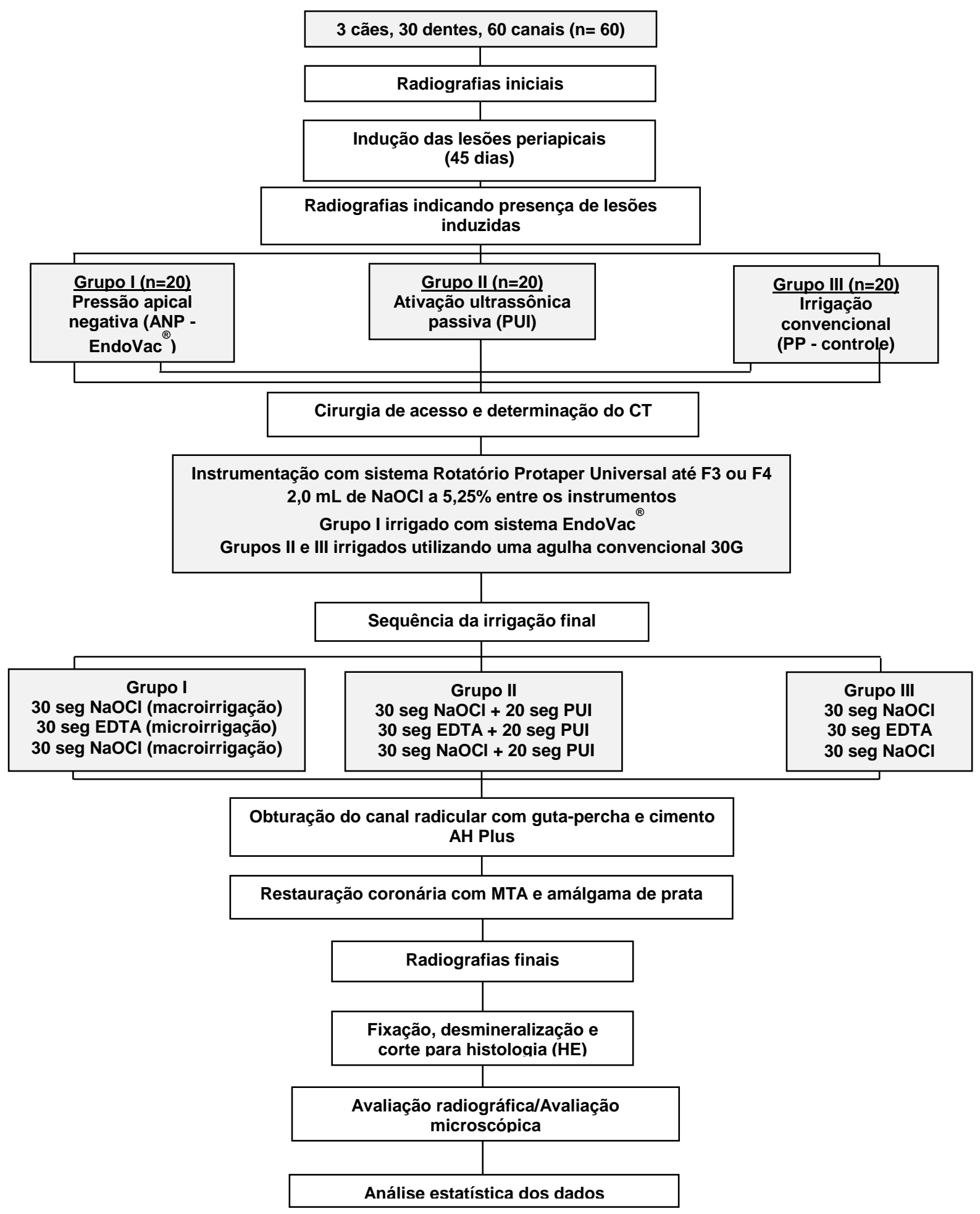

Figura 1. Fluxograma representativo da metodologia empregada. 


\section{Avaliação Radiográfica}

O exame radiográfico periapical dos dentes utilizados neste estudo foi realizado de acordo com a técnica do paralelismo, previamente à indução das lesões periapicais, 45 dias após a contaminação inicial dos canais radiculares e 180 dias após o tratamento endodôntico, utilizando um dispositivo para padronização de tomadas radiográficas em cães (Cordeiro et al., 1995). Foram utilizados filmes periapicais Ultraspeed ${ }^{\circledR}$ de tamanho 2 (Siemens, New York, EUA), com 60 kVp e 10 $\mathrm{mA}$ e tempo de exposição de 1 segundo. As radiografias foram reveladas manualmente pelo método tempo / temperatura e arquivadas em cartelas plásticas.

Para a avaliação radiográfica quantitativa da reabsorção dos tecidos mineralizados, as imagens foram digitalizadas com auxílio de scanner óptico (Scanjet 7450 c series - Programa versão 3.0.2; a Hewlett-Packard; San Diego, USA), com resolução de 1.200 d.p.i. (dots per inch) e transferidas para o programa Image J 1.28 u (National Institutes of Health, Betheseda, USA) como descrito previamente (De Rossi et al., 2005; Silva et al., 2008; Paula-Silva et al., 2009). Com o objetivo de calibrar o programa, foi realizada a medida da distância da ponta da cúspide até a borda cervical da face distal de cada dente, com compasso de pontas secas, sendo essa medida transferida para o programa. A delimitação e a medida da área radiolúcida correspondente à lesão periapical, presente em cada raiz, foi determinada em $\mathrm{mm}^{2}$. A avaliação foi realizada por 1 examinador calibrado $(k=0,96)$ e cego. A porcentagem de redução das lesões periapicais foi calculada para cada grupo, sendo os grupos comparados entre si por meio do teste de Kruskal-Wallis. $\mathrm{O}$ nível de significância adotado foi de $5 \%$. Uma breve análise descritiva das características radiográficas apicais e periapicais foi também realizada.

\section{Processamento Histotécnico e Avaliação Microscópica}

Decorridos 180 dias, os animais foram submetidos à eutanasia por sobredose endovenosa de pentobarbital sódico. As maxilas e mandíbulas contendo os dentes foram dissecadas e seccionadas para se obter raízes individuais, as quais foram fixadas em formalina tamponada a $10 \%$ por 48 horas à temperatura ambiente e, em seguida, lavadas por, aproximadamente, 8 horas em água corrente. Em 
seguida, para a descalcificação das peças, foi utilizada solução à base de EDTA a $20 \%$ (pH 7,4). As peças foram mantidas nesta solução, à temperatura ambiente, trocada semanalmente. A completa descalcificação das amostras, avaliada por meio da penetração de uma agulha nos tecidos para verificação da sua consistência, foi obtida em aproximadamente 30 dias. Concluída a descalcificação, as peças foram neutralizadas em solução de sulfato de sódio a 5\% (Sulfato de Sódio Anhidro; J.T.Baker, Xalostoc, México) por 24 horas, lavadas em água corrente por 12 horas, desidratadas em concentrações crescentes de álcool (Álcool Etílico Absoluto Anhidro; J.T.Baker), diafanizadas em xilol (Xilol; Merck) e incluídas em parafina (Histosec Pastillen; Merck). Os blocos contendo os dentes foram cortados longitunalmente em micrótomo (Leica RM2145; Leica Microsystems GmbH, Wetzlar, Alemanha) no sentido mésio-distal. Cortes semi-seriados de $5 \mu \mathrm{m}$, com intervalos de $15 \mu \mathrm{m}$, foram obtidos em toda a extensão da lesão periapical, exceto na região do forame apical, onde todos os cortes foram coletados sem intervalos e, então, corados com hematoxilina e eosina (HE).

A análise dos cortes foi efetuada em microscópio AXIO IMAGER.M1 (Zeiss, Göttingen, Germany) acoplado a uma câmera AXIOCAM MRc5 (Zeiss, Göttingen, Germany). A avaliação foi realizada por meio de escores, de acordo com seguintes parâmetros histopatológicos: a) Espessura do ligamento periodontal na região apical: normal (escore 1), levemente aumentada (escore 2), moderadamente aumentada (escore 3) ou severamente aumentada (escore 4); b) Infiltrado inflamatório: normal (escore 1), suave (escore 2), moderado (escore 3) ou severo (escore 4); c) Processo de reabsorção dos tecidos mineralizados: ausente (escore 1) ou presente (escore 2). Uma descrição completa das características das regiões apicais e periapicais de cada grupo foi também realizada.

\section{Morfometria em Microscopia de Fluorescência}

A análise morfométrica da extensão das lesões periapicais, em todos os grupos, foi realizada nos espécimes corados com HE, utilizando o microscópio Axio Imager.M1, em aumento de 1,25x, operando no modo fluorescente, conforme descrito por De Rossi et al. (2007). Foi utilizado filtro Alexa Fluor 488 (AF488) com as seguintes características: excitação de G365, refletores FT395 e emissão LP420. Para cada espécime, a extensão (área) da lesão periapical foi delineada e 
mensurada em $\mathrm{mm}^{2}$, empregando o software Axio Vision Rel 4.8. A delimitação da lesão excluiu as estruturas intactas (ligamento periodontal, cemento e osso alveolar), facilmente identificadas pela forte fluorescência verde, e incluiu áreas de reabsorção e infiltrado inflamatório, identificadas pela ausência de fluorescência e aparência escurecida.

\section{Histoenzimologia para Fosfatase Ácida Resistente ao Tartarato (TRAP)}

Para a marcação de células gigantes multinucleadas (osteoclastos), foi utilizada a atividade da TRAP (Burstone, 1959; Silva et al., 2012). Os cortes foram desparafinizados (2 banhos de xilol de 5 minutos cada) e hidratados (álcool 100\% por duas vezes de 5 minutos cada; alcoóis 95, 70 e 50\% por dois minutos cada e água destilada pelo mesmo período). A seguir, as lâminas foram colocadas em solução de álcool/acetona a $50 \%$ durante um minuto e os cortes secos à temperatura ambiente. Em seguida, uma solução contendo $10 \mathrm{~mL}$ de tampão de ácido acético, 0,1 $\mathrm{mL}$ de dimetilformamida, $5 \mathrm{mg}$ de Fast-red e $1 \mathrm{mg}$ de ácido fosfórico naftol AS-BI (Sigma-Aldrich Corporation, Saint Louis, EUA) foi pipetada sobre os cortes, que foram mantidos protegidos da luz em estufa a $37^{\circ} \mathrm{C}$ por, aproximadamente, 40 minutos. Após a incubação foi realizada a contra-coloração com azul de anilina por um minuto. A seguir, as lâminas foram montadas e avaliadas no microscópio Axio Imager.M1 sob luz convencional, para contagem do número de células TRAP-positivas presentes nas lacunas de reabsorção, em contato direto com o osso alveolar ao redor da lesão periapical, sendo expressas em número de células.

\section{Coloração de Brown e Brenn}

Os cortes foram inicialmente desparafinizados (3 banhos de xilol de 8 minutos cada), hidratados (banhos com alcoóis a 100, 95 e 80\%), lavados em água corrente por, aproximadamente, 3 minutos, e colocados em um recipiente com água destilada. A solução de violeta cristal tamponada com bicarbonato de sódio a $5 \%$ foi aplicada sobre os cortes por 30 segundos e, em seguida, as lâminas foram lavadas com água destilada. A seguir, as lâminas foram mergulhadas em solução de iodo de 
Gram por um minuto e lavadas com água destilada. Após a remoção do excesso de água destilada com papel absorvente, as lâminas passaram por uma solução de éter-acetona (proporção 1:1) para remoção do excesso de corantes e, novamente, foram lavadas com água destilada. Em seguida, as lâminas foram colocadas em fucsina básica, durante um minuto, lavadas com água destilada, colocadas em ácido pícrico aquoso, por um minuto, lavadas e secas com papel absorvente. Posteriormente, as lâminas foram mergulhadas em solução de acetona P.A., para remoção do excesso de corantes, e em solução de acetona-xilol. A seguir, foi realizada a diafanização, a desidratação e a montagem das lâminas com lamínula e entellan.

Essa coloração foi utilizada para avaliar a presença ou ausência de bactérias e sua localização, de acordo com a técnica de Brown e Brenn (1931) modificada por Taylor, em 1966. Para esta avaliação foram atribuídos escores de 0 a 4 (De Rossi et al., 2008) como descrito a seguir: ausência de bactérias (0); presença de bactérias no terço cervical da raiz (1); presença de bactérias no terço médio da raiz (2); presença de bactérias no terço apical da raiz (3); e presença de bactérias na lesão periapical (4).

Todas as análises foram efetuadas por examinadores experientes, sem conhecimento prévio do grupo que estava sendo avaliado.

\section{Análise Estatística}

Para a comparação dos resultados obtidos, nos diferentes grupos, com relação à análise morfológica por meio de escores e às variáveis numéricas (morfometria em microscopia de fluorescência e TRAP) foi utilizado o teste nãoparamétrico de Kruskal-Wallis e, quando necessário, o pós-teste de Dwass-SteelChritchlow-Fligner. Todas as análises foram realizadas com nível de significância de $5 \%$. 
Resultados 



\section{Resultados}

\section{Avaliação Radiográfica}

Previamente à indução das lesões periapicais, a lâmina dura apresentava-se íntegra em todos os dentes de todos os grupos e não existiam áreas radiolúcidas indicativas de lesão periapical ou de reabsorção radicular, em nenhum espécime.

Aos 45 dias após a contaminação dos canais radiculares, nos espécimes de todos os grupos foi detectada descontinuidade da lâmina dura e presença de áreas radiolúcidas sugestivas de lesão periapical. Em alguns casos, também foi possível observar a presença de reabsorção radicular externa.

Aos 180 dias após o tratamento endodôntico dos canais radiculares, o exame radiográfico permitiu detectar a permanência de áreas radiolúcidas sugestivas de lesão periapical e descontinuidade da lâmina dura, na maioria dos espécimes dos 3 grupos avaliados. Apenas 4 espécimes do grupo I (ANP), 1 espécime do grupo II (PUI) e 1 espécime do grupo III (PP) não apresentaram áreas radiolúcidas sugestivas de lesão periapical e descontinuidade da lâmina dura. Entretanto, pôdese notar uma redução no tamanho das lesões periapicais e a presença de trabeculado ósseo ligeiramente mais denso, na maioria dos casos, sugerindo uma melhora na resposta tecidual periapical, quando em comparação às radiografias anteriores ao tratamento, em todos os grupos. Em alguns casos, também foi possível observar a presença de reabsorção radicular externa.

A redução no tamanho das lesões periapicais foi confirmada por meio da análise radiográfica quantitativa da reabsorção dos tecidos mineralizados. A Figura 2 mostra a distribuição do porcentual de redução no tamanho das lesões periapicais para cada grupo. No grupo I (ANP), houve redução de $21,46 \%$ no tamanho das lesões periapicais. No grupo II (PUI), houve redução de $30,19 \%$ e no grupo III (PP) houve redução de 30,03\% no tamanho das lesões periapicais.

Não foi possível encontrar diferença estatisticamente significante na porcentagem de redução no tamanho das lesões periapicais pós-tratamento, ao comparar os resultados dos 3 grupos $(p=0,91)$. 


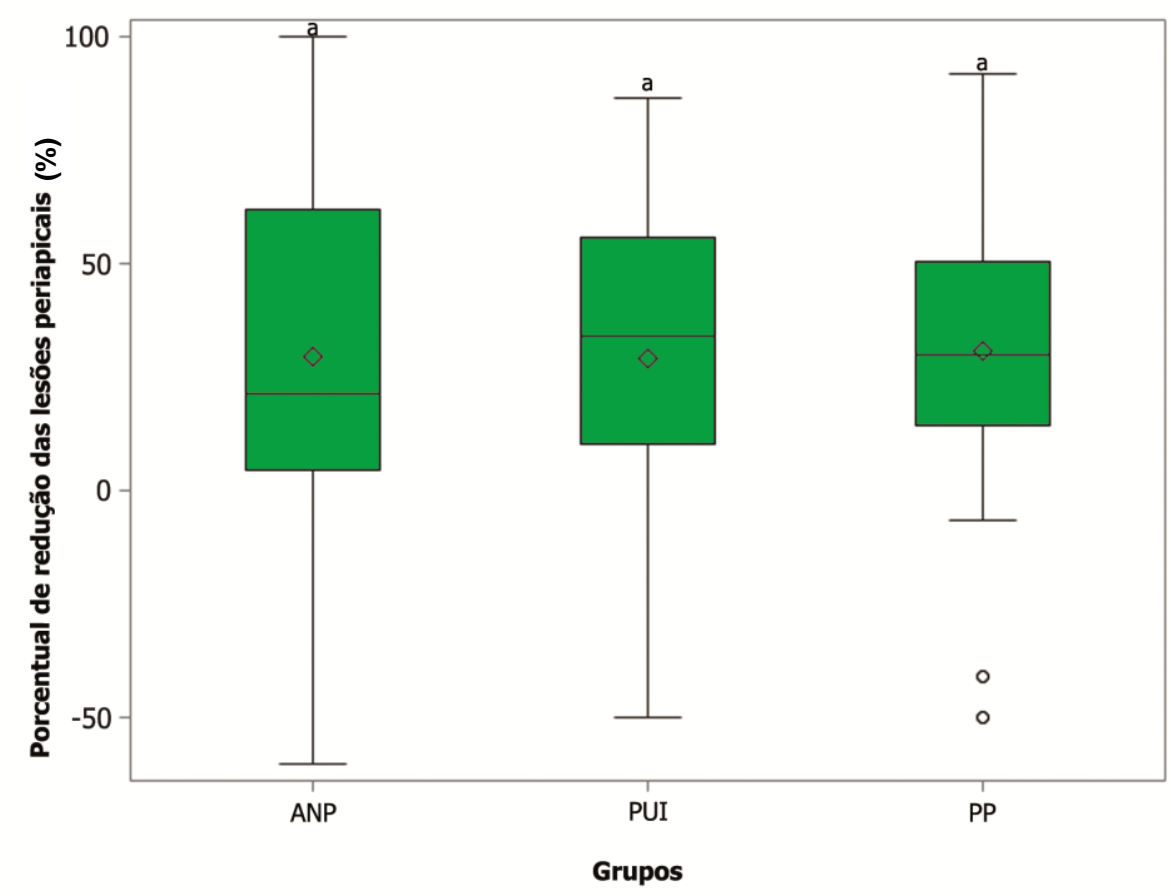

Figura 2. Porcentual de redução radiográfica das lesões periapicais, 180 dias após a realização do tratamento endodôntico, nos grupos I (EndoVac ANP), II (Ultrassom - PUI) e III (Irrigação convencional - PP). Letras iguais indicam que não houve diferença estatisticamente significante na comparação entre os grupos $(p=0,91)$.

\section{Avaliação microscópica descritiva e morfométrica da região periapical}

Para a avaliação microscópica descritiva e morfométrica da região periapical foram considerados 17 espécimes do grupo I (ANP), 15 espécimes do grupo II (PUI) e 17 do grupo III (PP), tendo em vista perdas ocorridas durante o processamento histotécnico.

De acordo com a análise descritiva subjetiva, verificou-se que o grupo I foi o que apresentou resultados mais homogêneos, evidenciando ligamento periodontal moderadamente aumentado e infiltrado de células inflamatórias do tipo suave na maioria dos espécimes (11 e 13 casos, respectivamente), presenças de fibras e edema reduzido. Houve também predomínio da ausência de processos reabsortivos de tecidos mineralizados (13 casos), com células osteoblásticas revestindo a superfície óssea voltada para a lesão periapical, na maioria dos espécimes.

No grupo II não houve uniformidade na resposta tecidual. Com relação à espessura do ligamento periodontal, observou-se espaço normal em 1 espécime, levemente aumentado em 4, moderadamente aumentado em 6 e severamente aumentado em 4 espécimes. Com relação ao infiltrado inflamatório, nesse grupo 
houve predomínio de infiltrado suave (10 casos), de maneira semelhante ao grupo I. Não foi observado processo de reabsorção de tecidos mineralizados em 8 dos 15 espécimes avaliados. Nos 7 espécimes que apresentaram processo de reabsorção, havia presença reduzida de fibras e edema moderado, sendo que a superfície óssea voltada para a lesão periapical encontrava-se desnuda, com presença de lacunas de reabsorção e células osteoclásticas.

À semelhança do grupo II, no grupo III também não foi observado uniformidade na resposta tecidual com relação ao espaço do ligamento periodontal. Em 6 espécimes o espaço estava levemente aumentado, em 7 estava moderadamente aumentado e em 4 espécimes severamente aumentado. Com relação ao infiltrado inflamatório, houve predomínio de infiltrado moderado (9 casos). Não foi observado processo de reabsorção de tecidos mineralizados em 9 dos 17 espécimes avaliados. Nos 8 espécimes que apresentaram processo de reabsorção, havia escassa presença de fibras e edema moderado.

No entanto, de acordo com os escores obtidos durante a análise histopatológica, não foi possível encontrar diferença estatisticamente significante entre os 3 grupos com relação ao espaço do ligamento periodontal $(p=0,66)$ e à presença do processo de reabsorção dos tecidos mineralizados $(p=0,28)$. Por outro lado, com relação ao infiltrado inflamatório, foi possível encontrar diferença significante $(p=0,02)$ entre os grupos I e III, enquanto o grupo II foi semelhante aos grupos I e III, sendo o infiltrado mais intenso no grupo III, em comparação ao grupo I.

A Tabela 2 e as Figuras 3 e 4 apresentam os resultados obtidos após a análise microscópica da região periapical. 
Tabela 2. Escores dos parâmetros histopatológicos em cada grupo

Parâmetros Histopatológicos

\begin{tabular}{l|ll|l} 
Escores & Grupo I (ANP) & Grupo II (PUI) & Grupo III (PP)
\end{tabular}

Espaço do Ligamento Periodontal

Normal

Levemente aumentado

$1 \quad 0$

2

$3 \quad 11$

Moderadamente aumentado

4

no total de raízes

Análise estatística $(p=0,66)$

\section{Infiltrado Inflamatório}

Ausente

Suave

Moderado

Severo

$\mathrm{n}$ ํ total de raízes

Análise estatística $(p=0,02)$

Processo de Reabsorção de Tecidos

Mineralizados

$\begin{array}{lcccc}\text { Ausente } & 1 & 13 & 8 & 9 \\ \text { Presente } & 2 & 4 & 7 & 8 \\ \text { no total de raízes } & & 17 & 15 & 17 \\ \text { Análise estatística }(\mathrm{p}=0,28) & & \mathrm{a} & \mathrm{a} & \mathrm{a}\end{array}$

ANP (irrigação por Pressão Apical Negativa); PUI (Irrigação Ultrassônica Passiva); e PP (irrigação convencional por Pressão Positiva). Letras diferentes indicam diferença estatisticamente significante $(p<0,05)$. 

Figura 3. Fotomicrografias representativas dos 3 grupos avaliados (EndoVac - ANP, Ultrassom - PUI e Irrigação convencional - PP), evidenciando os eventos microscópicos observados na análise descritiva das regiões apical e periapical, 180 dias após a realização do tratamento endodôntico, em microscopia de luz convencional:

(A) Fotomicrografia panorâmica da região apical e periapical evidenciando espaço do ligamento periodontal (LP) moderadamente aumentado e osso alveolar (O) desnudo (HE, Zeiss, 5X).

(B) Detalhe da imagem A, onde observa-se ligamento periodontal (LP) com infiltrado inflamatório leve e intensa presença de fibras (HE, Zeiss, 20X).

(C) Fotomicrografia panorâmica da região apical e periapical evidenciando um espaço do ligamento periodontal (LP) severamente aumentado e osso alveolar (O) (HE, Zeiss, 5X).

(D) Detalhe da imagem $\mathrm{C}$, onde observa-se infiltrado inflamatório leve com intensa presença de fibras (HE, Zeiss, 20X).

(E) Detalhe da imagem C, onde observa-se superfície óssea revestida por osteoblastos (setas) (HE, Zeiss, 40X). 

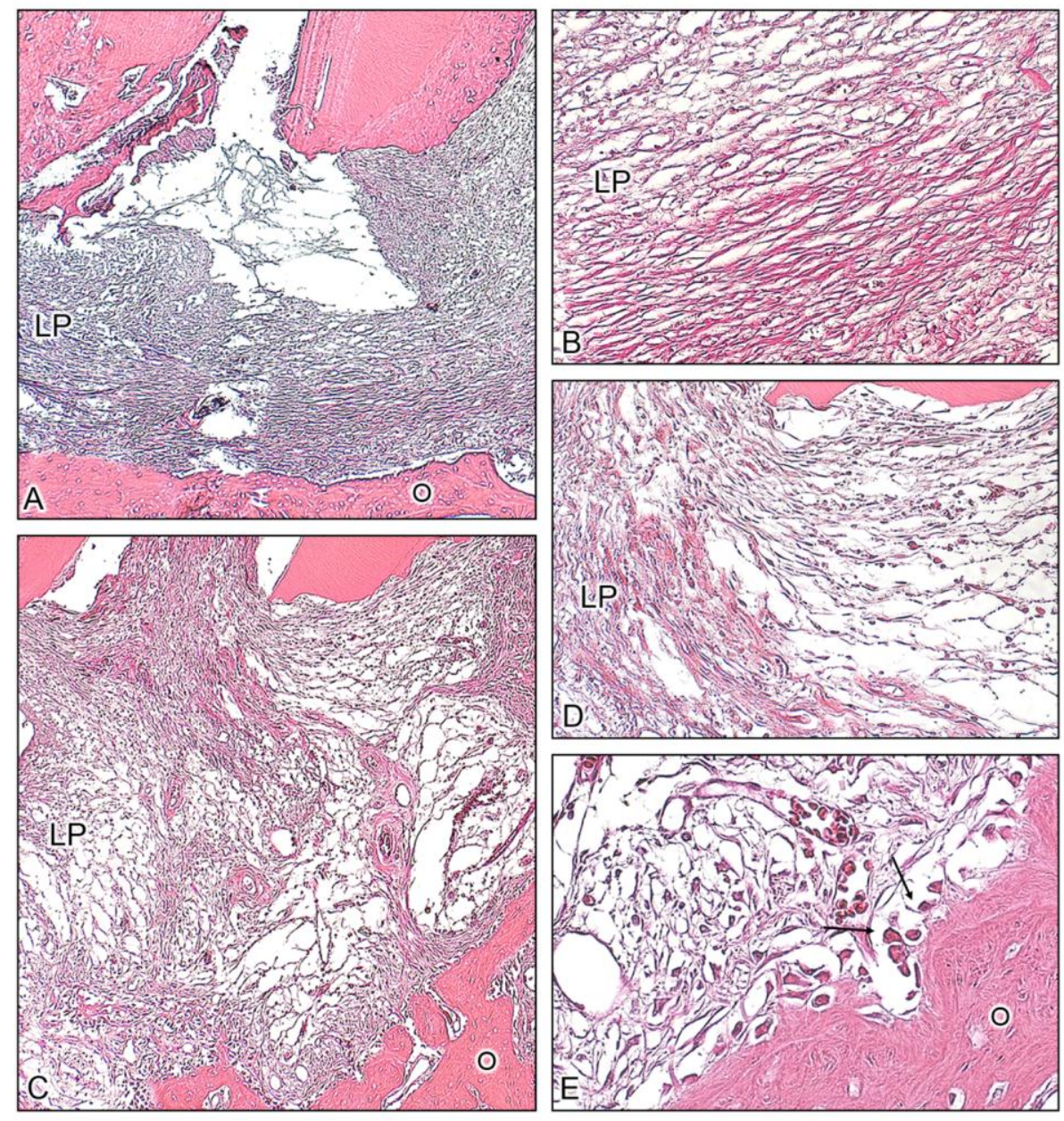


Figura 4. Fotomicrografias representativas dos 3 grupos avaliados (EndoVac-ANP, Ultrassom - PUI e Irrigação convencional - PP), evidenciando os eventos microscópicos observados durante a análise descritiva da região periapical, 180 dias após a realização do tratamento endodôntico, em microscopia de luz convencional:

(A) Ligamento periodontal (LP) com presença de infiltrado inflamatório leve (HE, Zeiss, 20X).

(B) Ligamento periodontal (LP) com presença de infiltrado inflamatório moderado (HE, Zeiss, 20X).

(C) Superfície do osso alveolar $(O)$ com presença de lacunas de reabsorção e osteoclastos (setas) (HE, Zeiss, 40X).

(D) Superfície do osso alveolar (O) revestida por camada de células osteoblásticas (setas) (HE, Zeiss, 20X).

(E) Radiografia periapical, após a indução das lesões periapicais, onde observa-se presença de áreas radiolúcidas sugestivas de lesão periapical (setas).

(F) Radiografia periapical, 180 dias após a realização do tratamento endodôntico, onde observa-se a permanência de áreas radiolúcidas sugestivas de lesão periapical (setas). 

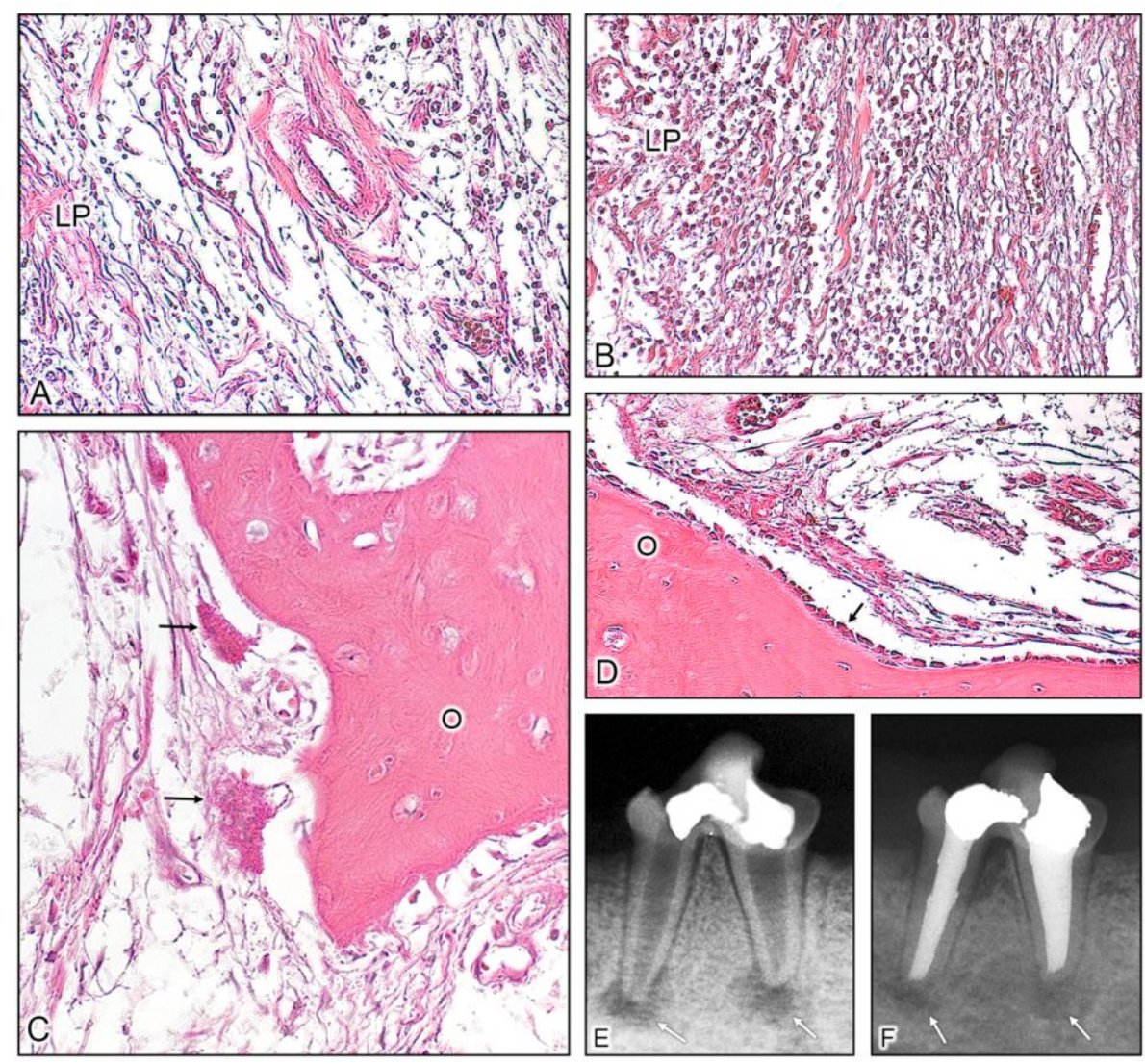

Com relação à análise morfométrica da extensão (área em $\mathrm{mm}^{2}$ ) das lesões periapicais por meio da microscopia de fluorescência (Figura 5), não foi possível encontrar diferença estatisticamente significante entre os grupos $(p=0,92)$. O grupo I (ANP) apresentou mediana de $9,94 \mathrm{~mm}^{2}$, o grupo II (PUI) de $6,3 \mathrm{~mm}^{2}$ e o grupo III (PP) de 8,0mm², 180 dias após a realização do tratamento endodôntico (Figura 6). 
Figura 5. Fotomicrografias dos cortes microscópicos representativos dos 3 grupos (EndoVac - ANP, Ultrassom - PUI e Irrigação convencional - PP), 180 dias após a realização do tratamento endodôntico, corados com hematoxilina e eosina. Em A, C e E, as imagens foram observadas em microscopia de luz convencional e em B, D e F, as imagens foram analisadas no modo fluorescente para mensuração da área das lesões periapicais, como delimitado nas figuras (HE, Zeiss, 1,25X). 


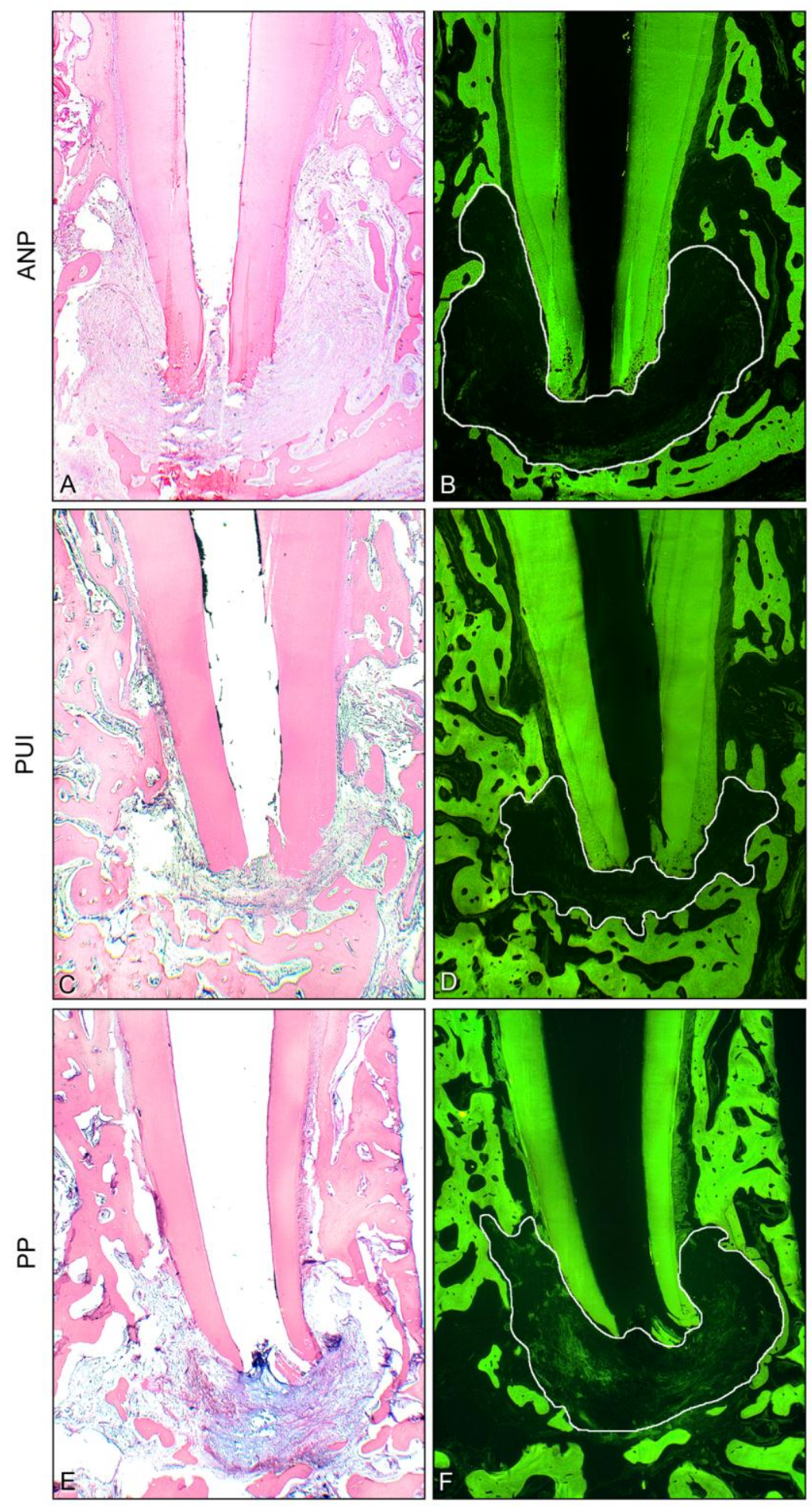





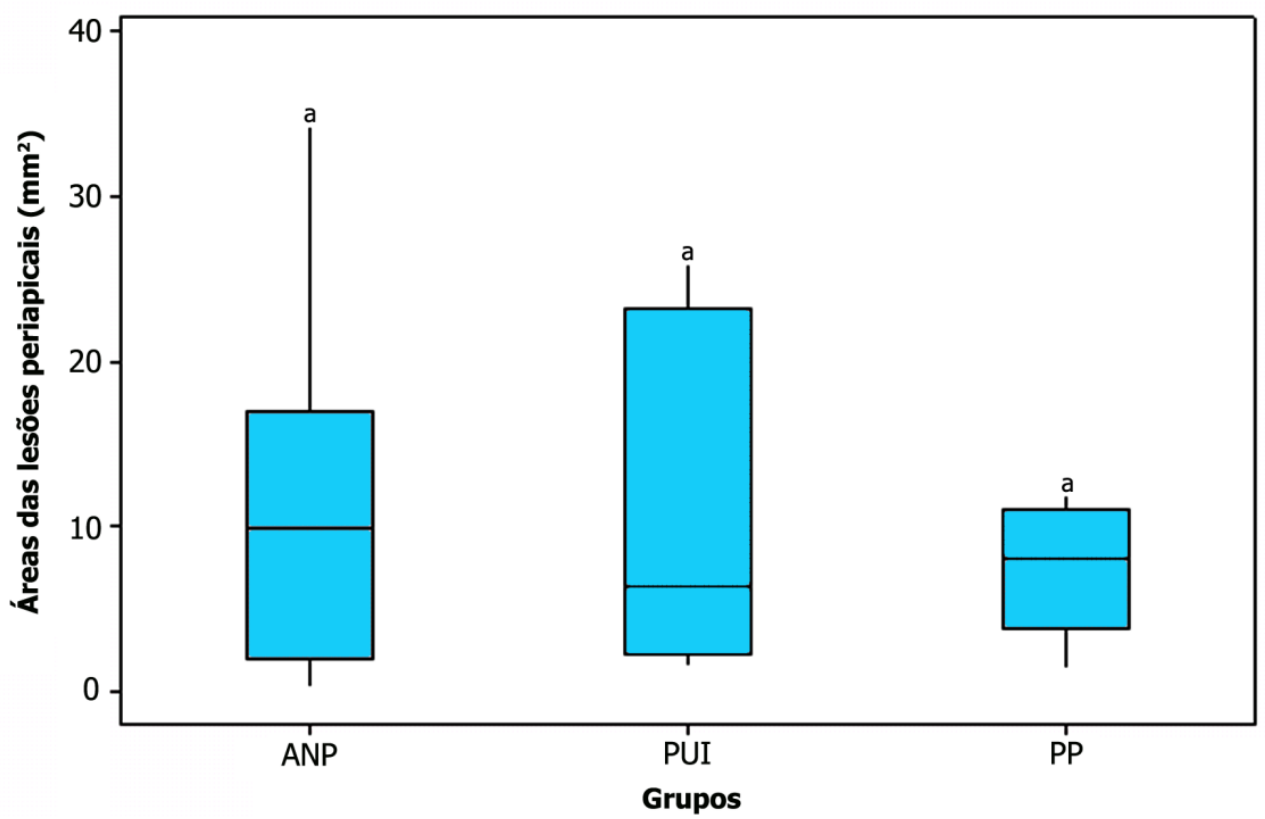

Figura 6. Representação gráfica da comparação dos resultados obtidos após mensuração da área das lesões periapicais, em microscopia de fluorescência, entre os grupos I (EndoVac - ANP), II (Ultrassom- PUI) e III (Irrigação convencional - PP), 180 dias após a realização do tratamento endodôntico. Letras iguais indicam que não houve diferença estatisticamente significante na comparação entre os grupos $(p=0,92)$.

\section{Histoenzimologia TRAP}

Com relação ao número de células gigantes multinucleadas (osteoclastos), não foi possível encontrar diferença estatística significante $(p=0,58)$ entre os grupos. A Tabela 3 e a Figura 7 mostram a distribuição dos valores numéricos das células TRAP-positivas presentes nas lacunas de reabsorção, em contato direto com o osso alveolar ao redor da lesão periapical. A Figura 8 ilustra os dados obtidos.

Tabela 3. Número de osteoclastos (células TRAP-positivas) nas lacunas de reabsorção, em contato direto com o osso alveolar ao redor da lesão periapical

\begin{tabular}{lccc} 
Tratamentos & Mediana & Mínimo & Máximo \\
EndoVac (ANP) & 6,00 & 2,00 & 29,00 \\
Ultrassom (PUI) & 8,00 & 2,00 & 13,00 \\
Irrigação convencional (PP) & 9,00 & 4,00 & 15,00 \\
\hline
\end{tabular}




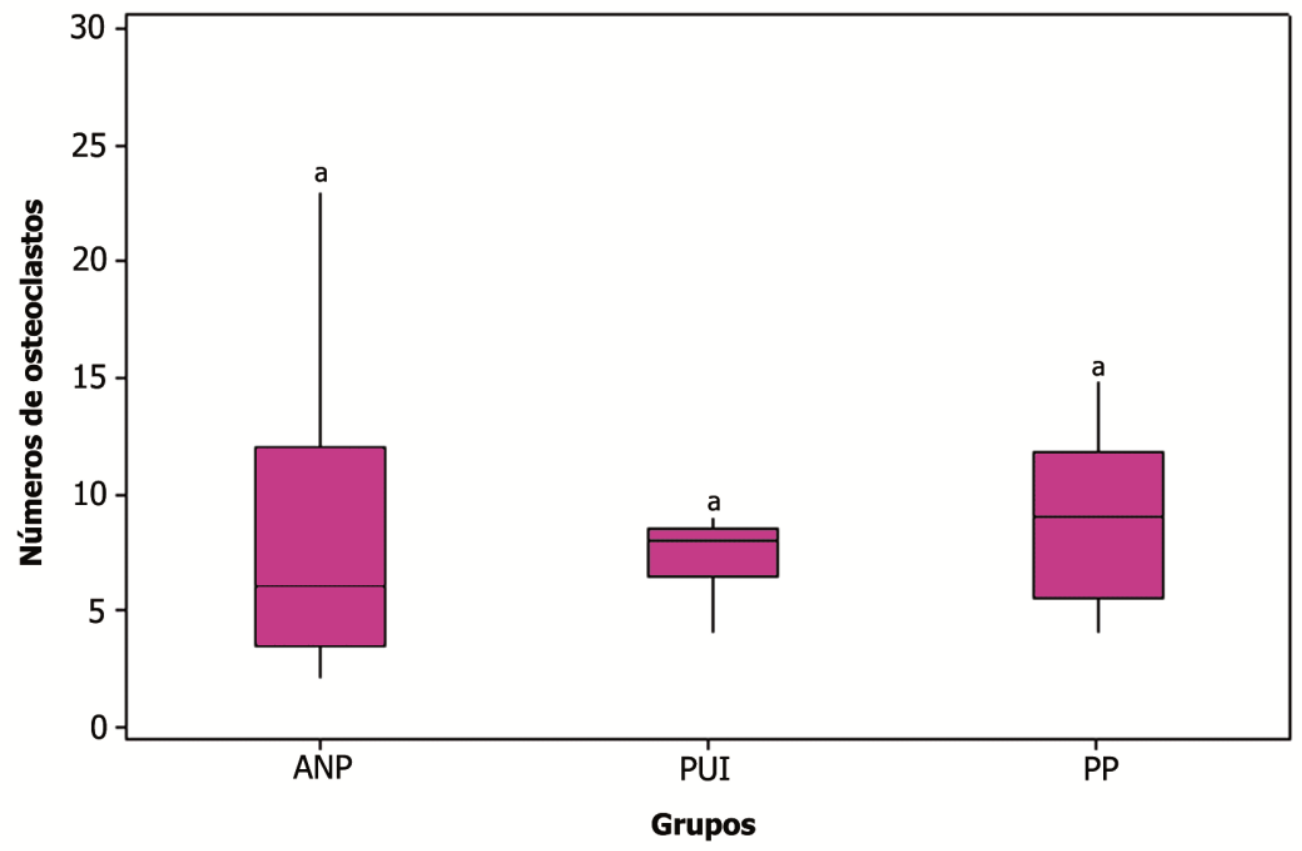

Figura 7. Distribuição do número de osteoclastos (células TRAP-positivas) nas lacunas de reabsorção, em contato direto com o osso alveolar. Letras iguais indicam que não houve diferença estatisticamente significante na comparação entre os grupos $(\mathrm{p}=0,58)$. ANP (EndoVac); PUI (Ultrassom); e PP (Irrigação convencional). 

Figura 8. Fotomicrografias dos cortes microscópicos representativos dos 3 grupos avaliados (EndoVac - ANP, Ultrassom - PUI e Irrigação convencional PP), 180 dias após a realização do tratamento endodôntico, corados por meio da técnica de histoenzimologia para a atividade da fosfatase ácida resistente ao tartarato (TRAP) para identificação e contagem de células osteoclásticas:

(A) Fotomicrografia panorâmica da região apical e periapical, onde observa-se a luz do canal radicular (LC), dentina (D), ligamento periodontal (LP) e osso alveolar (O) (Zeiss, 1,25X).

(B) Osteoclastos (vermelho) presentes no osso alveolar (O) ao redor da lesão periapical (Zeiss, 20X).

(C), (D) e (E) Osteoclastos (vermelho) presentes no osso alveolar (O) ao redor da lesão periapical (Zeiss, 40X). 

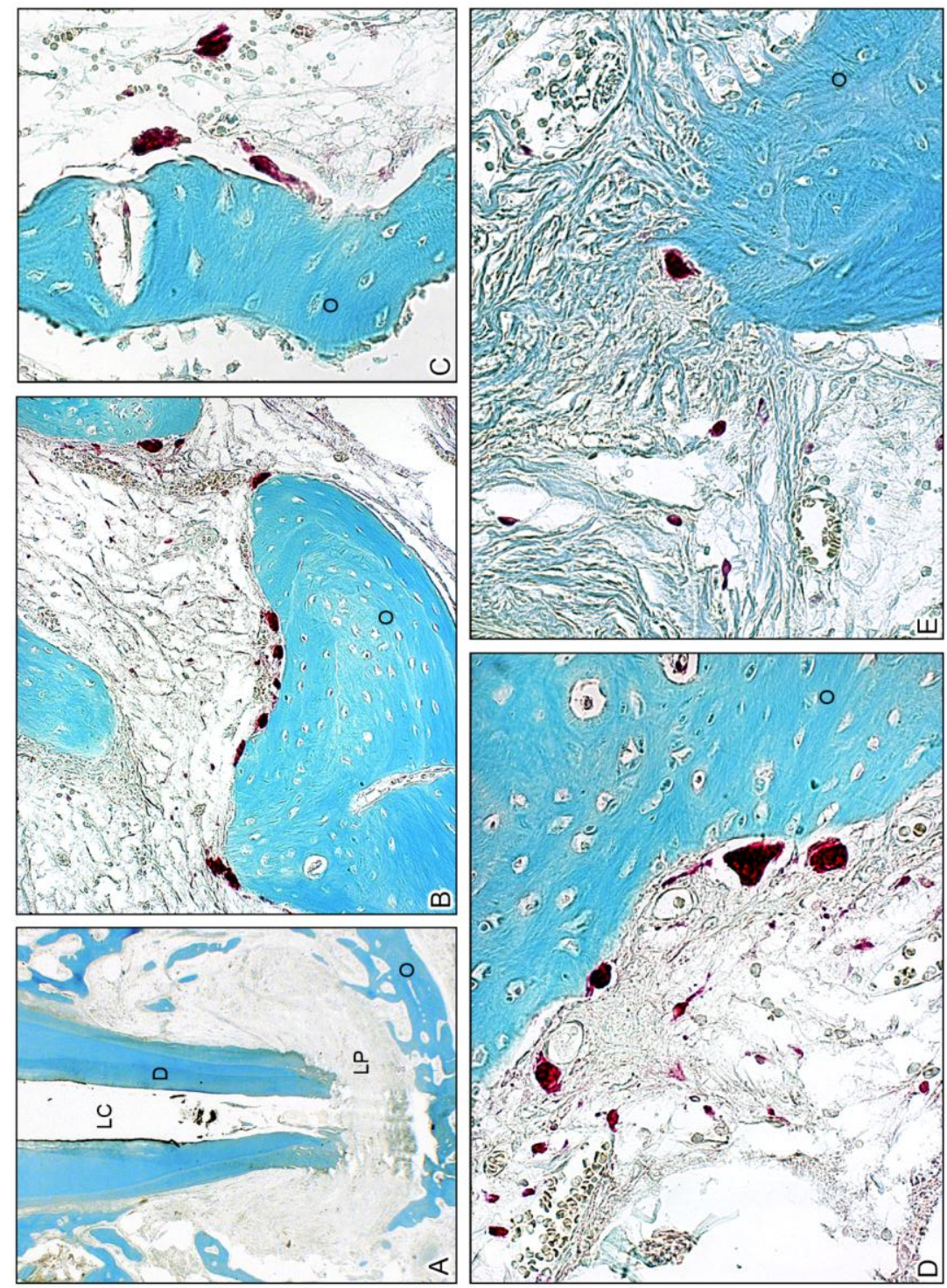



\section{Coloração de Brown e Brenn}

Intensa presença de micro-organismos foi observada no terço radicular cervical, assim como nos terços médio e apical, nos espécimes dos 3 grupos (I, II e III) com micro-organismos disseminados pelo sistema de canais radiculares, frequentemente penetrando os túbulos dentinários (escores 1 a 3). Além disso, em todos os grupos houve espécimes que exibiram bactérias na lesão periapical (escore 4). Nos grupos I, II e III, 13 espécimes (76\%), 11 espécimes (73\%) e 12 espécimes (71\%) apresentaram, respectivamente, bactérias na lesão periapical.

A figura 9 representa a presença bacteriana nas diferentes regiões do sistema de canais radiculares. 
Figura 9. Fotomicrografias representativas dos cortes microscópicos dos 3 grupos avaliados (EndoVac - ANP, Ultrassom - PUI e Irrigação convencional PP), corados com a técnica de Brown e Brenn, evidenciando a presença e a localização bacteriana no sistema de canais radiculares e nos tecidos periapicais, 180 dias após a realização do tratamento endodôntico:

(A) Fotomicrografia panorâmica, demonstrando contaminação microbiana em toda a extensão do dente (Zeiss, 1,25X).

(B) Detalhe da imagem A (retângulo), onde observa-se o terço cervical da raiz com presença abundante de micro-organismos nos túbulos dentinários (Zeiss, 20X).

(C) Detalhe da imagem A (quadrado), evidenciando o terço médio da raiz com intensa presença microbiana (Zeiss, 20X).

(D) Detalhe da imagem A (círculo), onde observa-se o terço apical da raiz com micro-organismos nas crateras cementárias (seta) (Zeiss, 10X).

(E) Detalhe da imagem A (triângulo), onde observa-se presença abundante de micro-organismos no terço apical da raiz (Zeiss, 40X).

(F) Detalhe da imagem A (asterisco), evidenciando presença de microorganismos na lesão periapical (Zeiss, 20X). 


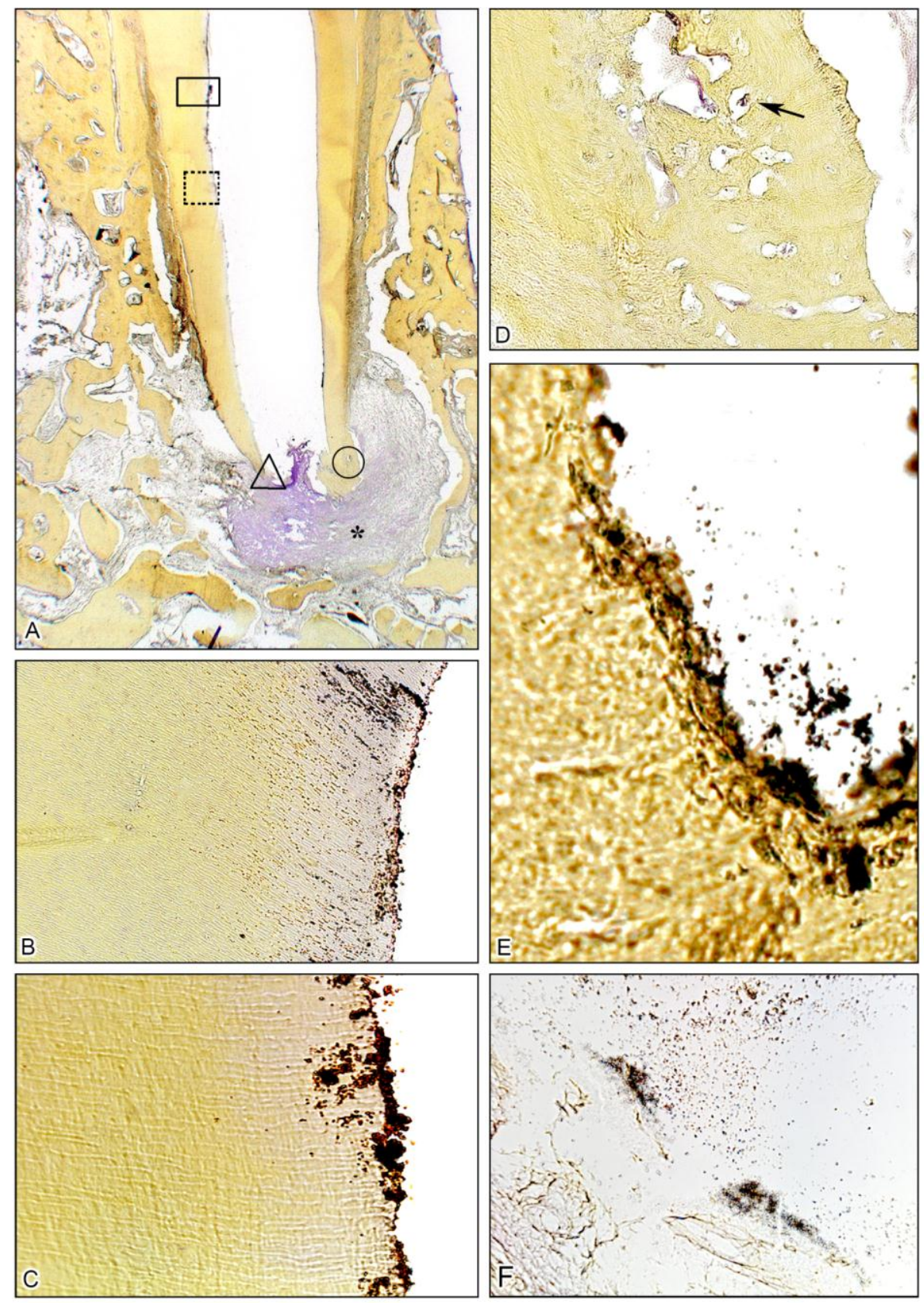



Discussão 



\section{Discussão}

Atualmente, diversas técnicas e dispositivos de irrigação têm sido utilizados com o objetivo de melhorar a limpeza e a desinfecção do sistema de canais radiculares. Considerando que, de acordo com a literatura específica, os sistemas de irrigação por Pressão Apical Negativa (ANP) e por Irrigação Ultrassônica Passiva (PUI) apresentam resultados promissores, principalmente com relação à limpeza e desinfecção do terço apical (Shin et al., 2010; De Gregório et al., 2010; BlankGonçalves et al., 2011), no presente estudo avaliou-se a resposta dos tecidos apicais e periapicais frente à sua utilização, em comparação à irrigação convencional realizada com Pressão Positiva (PP). Esses sistemas poderiam favorecer a resposta tecidual de dentes portadores de necrose pulpar e lesão periapical crônica visível radiograficamente.

Após o tratamento endodôntico, a resposta ideal dos tecidos apicais e periapicais de dentes com lesão periapical deveria incluir ausência de alterações no ligamento periodontal e nos tecidos mineralizados (cemento e osso alveolar), com formação da barreira apical de tecido mineralizado completa (selamento biológico) (Leonardo et al., 1993; Leonardo et al., 2003; Silva et al., 2010). Para avaliar esses aspectos, no presente estudo utilizamos parâmetros histomorfológicos e morfométricos, avaliados nas radiografias periapicais e nos cortes histológicos.

O exame radiográfico, apesar de suas limitações, é extremamente utilizado pela maioria dos cirurgiões-dentistas. Além disso, é uma parte importante do tratamento endodôntico e vêm sendo utilizado em diversos estudos para determinar o sucesso dos materiais e técnicas empregadas durante o tratamento endodôntico (Katebzadeh et al., 2000; De Rossi et al., 2005, Paula-Silva et al., 2009). Os resultados radiográficos quantitativos observados no presente estudo demonstraram redução no tamanho das lesões periapicais, de maneira similar entre os 3 sistemas de irrigação $(p>0,05)$. Assim, verificou-se que o uso de novos sistemas de irrigação (ANP e PUI) não elevou a porcentagem de redução das lesões periapicais após 180 dias, quando comparados à irrigação com PP. No grupo irrigado com ANP, PUI e PP houve redução de $20,39 \%, 30,19 \%$ e $30,03 \%$, respectivamente, no tamanho das lesões periapicais, radiograficamente. Assim, de acordo com os resultados radiográficos obtidos, observou-se que não houve reparação completa da área da 
lesão periapical após tratamento em sessão única, com nenhum dos sistemas de irrigação utilizados.

Por outro lado, sabe-se que o osso é um tecido dinâmico que sofre constante remodelação ao longo da vida e, em condições patológicas, quando há perda óssea, como nos casos de lesões periapicais crônicas, o processo de reabsorção é superior à formação óssea. Um dos achados característicos dessa condição é o acúmulo crescente de osteoclastos nas áreas de reabsorção óssea (Walsh et al., 2006). No presente estudo em dentes de cães com rizogênese completa e presença de lesão periapical crônica, não foi possível observar diferenças na quantidade de osteoclastos entre os diferentes tipos de sistema de irrigação avaliados $(p=0,58)$, após a histoenzimologia para a marcação da atividade da TRAP, que permite identificar a presença de dessas células nas áreas de reabsorção óssea.

Além disso, embora o uso da ANP tenha ocasionado uma resposta microscópica subjetiva mais favorável, com relação à ocorrência do processo de reparo na análise descritiva da região periapical, não foi observada diferença estatisticamente significante na maioria dos parâmetros histopatológicos avaliados, em comparação à PUl e à PP. Houve diferença estatisticamente significante apenas com relação à intensidade do infiltrado inflamatório, onde o grupo ANP apresentou infiltrado inflamatório mais suave em comparação à PP, não havendo diferença em relação à PUI.

No presente estudo, a maioria dos espécimes de todos os grupos apresentou lesões periapicais visíveis radiograficamente e, também, por meio da morfometria por microscopia de fluorescência, mesmo após 180 dias da realização do tratamento endodôntico. Além disso, a maioria dos espécimes de todos os grupos apresentou aumento do espaço do ligamento periodontal, presença de infiltrado inflamatório, presença de bactérias no sistema de canais radiculares e na região periapical e alguns espécimes com reabsorções dentárias e ósseas. A presença de desfechos desfavoráveis após o tratamento endodôntico neste estudo pode ser atribuída, possivelmente, à ausência da realização de um curativo de demora antimicrobiano, entre as sessões, uma vez que o tratamento foi realizado em sessão única, visando apenas à análise comparativa da eficácia dos diferentes sistemas de irrigação.

Nossos resultados corroboram com estudos histopatológicos prévios que avaliaram a irrigação convencional por PP, em dentes de cães com lesão periapical crônica. De Rossi et al. (2005) observaram presença de lesão periapical, de infiltrado 
inflamatório e de áreas de reabsorção de superfície no grupo irrigado com $\mathrm{NaOCl}$ a 2,5\% e obturado em sessão única, 120 dias após a realização do tratamento endodôntico. Paula-Silva et al. (2009), utilizando essa mesma concentração de $\mathrm{NaOCl}$, observaram presença de reabsorção radicular externa no cemento e na dentina em $80 \%$ dos espécimes avaliados, infiltrado inflamatório além da metade da extensão do ligamento periodontal e presença de áreas radiolúcidas sugestivas de lesões em todos os espécimes avaliados, 180 dias após a realização do tratamento endodôntico. Da mesma forma, em estudo realizado por Silveira et al. (2007) a maioria dos espécimes do grupo tratado em sessão única apresentou inflamação e áreas de reabsorção radicular ativa em alguns espécimes. Sabeti et al. (2006) utilizando a mesma concentração de $\mathrm{NaOCl}$ do presente estudo $(5,25 \%)$ observaram presença de reabsorção óssea $44 \%$ dos espécimes, sendo que $60 \%$ apresentaram infiltrado inflamatório moderado e apenas $4 \%$ apresentaram espessura do ligamento periodontal normal, 190 dias após a realização do tratamento endodôntico.

Embora o sistema de irrigação por pressão positiva (PP) seja o sistema mais utilizado na Endodontia, sua eficácia é restrita tanto por limitações físicas (sistema fechado de canais), quanto pela complexidade do sistema de canais radiculares, especialmente na região apical. É bem estabelecido que a efetividade do sistema de irrigação por PP (irrigação convencional) é dependente da penetração e do volume da solução irrigante (Chow, 1983; Tay et al., 2010). Quanto mais profunda for a introdução da agulha no canal radicular melhor a capacidade de limpeza. Contudo, isso traria maior risco de lesionar os tecidos periapicais, devido à possível extrusão da solução irrigadora (Mitchell et al., 2011).

De acordo com a literatura específica, o sistema EndoVac ${ }^{\circledR}$ (ANP) é o único que promove extrusão limitada ou nenhuma extrusão da solução irrigadora além do forame apical (Fukumoto et al., 2006; Desai e Himel, 2009; Mitchell et al., 2011). Além disso, é mais efetivo na remoção de debris e na liberação de solução irrigadora no comprimento de trabalho, em comparação à PP (Shin et al., 2010; Munoz e Camacho-Cuadra, 2012; Ribeiro et al., 2012). Estudos in vitro também sugerem que o uso da ANP apresenta melhor capacidade de desbridamento, $1 \mathrm{~mm}$ aquém do ápice, em comparação à PP (Nielsen e Baumgartner, 2007; Siu e Baumgartner, 2010; Heilborn et al., 2010), não havendo diferença $3 \mathrm{~mm}$ aquém do ápice. Porém, Howard et al. (2011) não encontraram diferença significante na limpeza dos canais e 
dos istmos, quando se utilizou volumes similares de solução na irrigação final com EndoVac ${ }^{\circledR}$ ou PP, no comprimento de 2 e a $4 \mathrm{~mm}$ do ápice.

Entretanto, a grande maioria dos estudos avaliaram a ANP in vitro (Parente et al., 2009; Heilborn et al., 2010; Mitchell et al., 2011; Howard et al., 2011; Malentacca et al., 2012). Um único estudo histopatológico prévio foi realizado em dentes de cães com rizogênese incompleta, por Silva et al. (2010), verificando eficácia do sistema EndoVac ${ }^{\circledR}$ na revascularização dos tecidos apicais e periapicais. De acordo com o estudo de Silva et al. (2010), o sistema EndoVac ${ }^{\circledR}$ foi considerado um protocolo de desinfecção promissor em dentes com rizogênese incompleta e lesão periapical pois, em todos os canais radiculares, a avaliação histopatológica da região periapical evidenciou tecido conjuntivo bem estruturado, com denso infiltrado de fibroblastos e rico em vasos sanguíneos. Em alguns casos, houve formação de tecido mineralizado na região periapical com intensa revascularização e processo de reparo em estágio avançado, após 90 dias da realização do tratamento. Na maioria dos casos não havia células inflamatórias e o osso alveolar estava normal, com intensa presença de osteoblastos na superfície.

No entanto, os resultados do estudo histopatológico efetuado por Silva et al. (2010) não podem ser diretamente comparados aos do presente estudo, uma vez que foi realizado em dentes com rizogênese incompleta, os quais apresentam características histopatológicas diferentes de dentes com formação radicular completa. Nossos resultados, em dentes com rizogênese completa, estão de acordo com outras pesquisas, nas quais a ausência de resposta apical e periapical favorável têm sido relatadas após preparo biomecânico, incluindo irrigação com PP, e obturação do canal radicular em dentes com lesão periapical em uma sessão única (Leonardo et al., 1995; Trope et al., 1999; Katebzadeh et al., 1999; Tanomaru et al., 2002; Holland et al., 2003; De Rossi et al., 2005; Panzarini et al., 2006; PaulaSilva et al., 2009; Vera et al., 2012).

Por outro lado, de acordo com a literatura específica, o uso da PUI resulta em melhor desbridamento do sistema de canais radiculares, maior efetividade na liberação da solução irrigadora no comprimento de trabalho e maior remoção de smear layer em comparação à PP (Sabins et al., 2003; Lee et al., 2004; De Gregório et al., 2010; Malenttaca et al., 2012; Andrabi et al., 2013). Agrawal e Kapoor (2012), em estudo com microscopia eletrônica de varredura, demonstraram que a PUI associada ao $\mathrm{NaOCl}$ a $1,0 \%$ foi mais efetiva que a irrigação convencional com PP. 
Em estudo in vitro avaliando os mesmos sistemas de irrigação utilizados no presente trabalho, Ribeiro et al. (2012) relataram que os sistemas que utilizam o método de agitação ultrassônica e o EndoVac $^{\circledR}$ removeram mais debris que a técnica convencional. Munoz e Camacho-Cuadra (2012), em estudo in vivo, relataram que a PUI e a ANP foram mais efetivas na liberação de solução irrigadora no comprimento de trabalho em molares inferiores de humanos. Porém, Howard et al. (2011) não encontraram diferença significante na limpeza dos canais e dos istmos, quando se utilizou volumes similares de solução irrigadora na irrigação final com EndoVac ${ }^{\circledR}$, ultrassom ou PP. Paiva et al. (2013) também relataram que uma abordagem complementar com a PUI não foi capaz de melhorar significativamente a desinfecção do sistema de canais radiculares, além daquela obtida pelos procedimentos convencionais de preparo biomecânico. No entanto, verificou-se que embora haja estudos in vitro e in vivo publicados, não há estudos histopatológicos avaliando a resposta dos tecidos periapicais após a utilização da PUI, dificultando uma comparação direta com os resultados obtidos no presente estudo.

É bem estabelecido que o controle da infecção do sistema de canais radiculares é fundamental para o sucesso do tratamento endodôntico e que o principal objetivo deve ser a redução da infecção microbiana a níveis onde o reparo possa ocorrer. Assim, no presente estudo, também foi realizada a marcação de bactérias por meio da coloração de Brown e Brenn. Uma grande vantagem deste método é que ele fornece informações sobre a localização anatômica das bactérias residuais, fornecendo subsídios para a avaliação das deficiências nas diferentes abordagens e permitindo o desenvolvimento de estratégias para melhorar a desinfecção do sistema de canais radiculares (Vera et al., 2012).

Os resultados do presente estudo mostraram que em todos os grupos houve presença de bactérias nas raízes dos canais radiculares e na região periapical, sugerindo que nenhuma técnica de irrigação promoveu a eliminação total dos microorganismos. Estes resultados estão de acordo com estudos histomicrobiológicos prévios. Silveira et al. (2007), em estudo em dentes de cães com lesão periapical utilizando essa mesma coloração, revelaram que a maioria dos casos no grupo tratado com PP, em sessão única, ainda abrigava bactérias nas paredes do canal radicular, no interior dos túbulos dentinários e na região do forame apical. Da mesma forma, Vera et al. (2012) observaram que todos os espécimes do grupo tratado com $\mathrm{PP}$, em sessão única, apresentaram bactérias residuais no sistema de canais 
radiculares, em estudo em dentes de humanos com lesão periapical. No entanto, até o momento também não há estudos histomicrobiológicos publicados na literatura utilizando a coloração de Brown e Brenn, após tratamento endodôntico com PUI ou ANP.

Em dentes portadores de necrose pulpar e lesão periapical, a persistência de infecção em áreas de difícil acesso pode comprometer a resposta dos tecidos apicais e periapicais. Os resultados do presente estudo demonstraram que o uso da ANP promoveu uma sutil melhora na resposta dos tecidos apicais e periapicais, após o tratamento endodôntico de dentes com necrose pulpar e lesão periapical crônica, em comparação à irrigação convencional com PP, não sendo possível encontrar diferença estatisticamente significante com relação à PUI.

Como já salientado, a escassez de trabalhos radiográficos, histopatológicos, histomicrobiológicos e histoenzimológicos avaliando a eficácia da ANP e da PUI dificulta a comparação dos resultados do presente estudo com achados prévios. Dessa forma, verifica-se que mais pesquisas são necessárias, incluindo estudos associando o uso da irrigação por pressão apical negativa e da irrigação ultrassônica passiva com diferentes medicamentos intracanais. 


\section{Conclusão}



Conclusão

Os resultados do presente estudo in vivo demonstraram que a irrigação por Pressão Apical Negativa (ANP) resultou em resposta inflamatória mais suave, em comparação ao grupo controle (irrigação convencional por Pressão Positiva - PP), porém, semelhante à Irrigação Ultrassônica Passiva (PUI). Nos demais aspectos (análise morfométrica radiográfica e por microscopia de fluorescência, histoenzimologia e histomicrobiologia), a resposta dos tecidos apicais e periapicais, após irrigação por ANP ou PUI, foi semelhante à irrigação convencional por PP. 

Referências 



\section{REFERÊNCIAS}

1- Abbott PV, Heijkoop PS, Cardaci SC, Hume WR, Heithersay GS. An SEM study of the effects of different irrigation sequences and ultrasonics. Int Endod J. 1991;24:308-16.

2- Abou-Rass M, Piccinino MV. The effectiveness of four clinical irrigation methods on the removal of root canal debris. Oral Surg Oral Med Oral Pathol. 1982;54:323-8.

3- Adcock JM, Sidow SJ, Looney SW, Liu Y, McNally K, Lindsey K, Tay FR. Histologic evaluation of canal and isthmus debridement efficacies of two different irrigant delivery techniques in a closed system. J Endod. 2011 Apr;37(4):544-8.

4- Agrawal VS, Kapoor S. An in vitro scanning electron microscopic study comparing the efficacy of passive ultrasonic and syringe irrigation methods using sodium hypochlorite in removal of debris from the root canal system. J Ir Dent Assoc. 2012 Jun-Jul;58(3):15661.

5- Al-Jadaa A, Paqué F, Attin T, Zehnder M. Necrotic pulp tissue dissolution by passive ultrasonic irrigation in simulated accessory canals: impact of canal location and angulation. Int Endod J. 2009;42:59-65.

6- Andrabi SM, Kumar A, Zia A, Iftekhar H, Alam S, Siddiqui S. Effect of passive ultrasonic irrigation and manual dynamic irrigation on smear layer removal from root canals in a closed apex in vitro model. J Investig Clin Dent. 2013 Apr 17.doi: 10.1111/jicd.12033. [Epub ahead of print]

7- Assed S, Ito IY, Leonardo MR, Silva LAB, Lopatin DE. Anaerobic microorganisms in root canals of human teeth with chronic apical periodontitis detected by indirect immunofluorescence. Endod Dent Traumatol. 1996;12:66-9.

8- Balto K. Single- or multiple-visit endodontics: which technique results in fewest postoperative problems? Evid Based Dent. 2009;10(1):16.

9- Blank-Gonçalves LM, Nabeshima CK, Martins GH, Machado ME. Qualitative analysis of the removal of the smear layer in the apical third of curved roots: conventional irrigation versus activation systems. J Endod. 2011;37:1268-71.

10- Bradley $\mathrm{BH}$, Cunningham $\mathrm{M}$. Biofilms in chronic wounds and the potential role of negative pressure wound therapy: an integrative review. J Wound Ostomy Continence Nurs. 2013 Mar;40(2):143-9.

11- Brown JH, Brenn L. A method for the differential staining of Gram-positive and Gramnegative bacteria in tissue sections. Bull. Johns Hopkins Hosp 1931;48:69-73.

12- Burleson A, Nusstein $J$, Reader A, Beck $M$. The in vivo evaluation of hand/rotary/ultrasound instrumentation in necrotic, human mandibular molars. J Endod. 2007;33:782-7.

13- Burstone MS. Histochemical demonstration of acid phosphatase activity in osteoclasts. J Histochem Cytochem. 1959 Jan;7(1):39-41. 
14- Cameron JA. The effect of ultrasonic endodontics on the temperature of the root canal wall. J Endod. 1988 Nov;14(11):554-9.

15- Chow TW. Mechanical effectiveness of root canal irrigation. J Endod. 1983;9:475-9.

16- Cohenca N, Heilborn C, Johnson JD, Flores DSH, Ito IY, Silva LAB. Apical negative pressure irrigation versus conventional irrigation plus triantibiotic intracanal dressing on root canal disinfection in the dog teeth. Oral Surg Oral Med Oral Pathol Oral Radiol Endod. 2010;109:e42-6.

17- Cohenca N, Paranjpe A, Heilborn C, Johnson JD. Antimicrobial efficacy of two irrigation techniques in tapered and non-tapered canal preparations. A randomized controlled clinical trial. Quintessence Int. 2013;44:217-28.

18- Cordeiro RCL, Leonardo MR, Silva LAB, Cerri PS. Desenvolvimento de um dispositivo para padronização de tomadas radiográficas em cães. RPG 1995;2:138-40.

19- De Gregorio C, Estevez R, Cisneros R, Heilborn C, Cohenca N. Effect of EDTA, sonic, and ultrasonic activation on the penetration of sodium hypochlorite into simulated lateral canals: an in vitro study. J Endod. 2009;35:891-5.

20- De Gregorio C, Estevez R, Cisneros R, Paranjpe A, Cohenca N. Efficacy of different irrigation and activation systems on the penetration of sodium hypochlorite into simulated lateral canals and up to working length: an in vitro study. J Endod. 2010;36:1216-21.

21- De Rossi A, Rocha LB, Rossi MA. Application of fluorescence microscopy on hematoxylin and eosin-stained sections of healthy and diseased teeth and supporting structures. J Oral Pathol Med. 2007 Jul;36(6):377-81.

22- De Rossi A, Rocha LB, Rossi MA. Interferon-gamma, interleukin-10, Intercellular adhesion molecule-1, and chemokine receptor 5 , but not interleukin-4, attenuate the development of periapical lesions. J Endod. 2008;34:31-8.

23- De Rossi A, Silva LA, Leonardo MR, Rocha LB, Rossi MA. Effect of rotary or manual instrumentation with or without a calcium hydroxide $/ 1 \%$ chlorhexidine intracanal dressing on the healing of experimentally induced chronic periapical lesions. Oral Surg Oral Med Oral Pathol Oral Radiol Endod. 2005;99:628-36.

24- Desai $P$, Himel V. Comparative safety of various intracanal irrigation systems. J Endod. 2009;35:545-9.

25- Fukumoto Y, Kikuchi I, Yoshioka T, Kobayashi C, Suda H. An ex vivo evaluation of a new root canal irrigation technique with intracanal aspiration. Int Endod J. 2006;39:93-9.

26- Gomes-Filho JE, Aurélio KG, Costa MM, Bernabé PF. Comparison of the biocompatibility of different root canal irrigants. J Appl Oral Sci. 2008;16:137-44.

27- Gondim E Jr, Setzer FC, Dos Carmo CB, Kim S. Postoperative pain after the application of two different irrigation devices in a prospective randomized clinical trial. J Endod. 2010 Aug;36(8):1295-301.

28- Goodman A, Reader A, Beck M, Melfi R, Meyers W. An in vitro comparison of the efficacy of the step-back technique versus a step-back/ultrasonic technique in human mandibular molars. J Endod. 1985;11:249-56. 
29- Gu LS, Kim JR, Ling J, Choi KK, Pashley DH, Tay FR. Review of contemporary irrigant agitation techniques and devices. J Endod. 2009;35:791-804.

30- Haapasalo M, Shen Y, Qian W, Gao Y. Irrigation in endodontics. Dent Clin North Am. 2010;54:291-312.

31- Heilborn C, Reynolds K, Johnson JD, Cohenca N. Cleaning efficacy of an apical negative-pressure irrigation system at different exposure times. Quintessence Int. 2010 Oct;41(9):759-67.

32- Holland R, Otoboni Filho JA, de Souza V, Nery MJ, Bernabe PF, Dezan E Jr. A comparison of one versus two appointment endodontic therapy in dogs' teeth with apical periodontitis. J Endod. 2003;29:121-4.

33- Howard RK, Kirkpatrick TC, Rutledge RE, Yaccino JM. Comparison of debris removal with three different irrigation techniques. J Endod. 2011 Sep;37(9):1301-5.

34- Hulsmann M, Hahn W. Complications during root canal irrigation--literature review and case reports. Int Endod J. 2000;33:186-93.

35- International Organization for Standardization (ISO). ISO 7405: Dentistry - Preclinical evaluation of biocompatibility of medical devices used in dentistry - Test methods for dental materials. Geneva: ISO; 1997.

36- Ito IY, Matoba Junior F, Paula-Silva FW, Da Silva LA, Leonardo MR, Nelson-Filho P. Microbial culture and checkerboard DNA-DNA hybridization assessment of bacteria in root canals of primary teeth pre- and post-endodontic therapy with a calcium hydroxide/chlorhexidine paste. Int J Paediatr Dent. 2011;21:353-60.

37- Jiang LM, Verhaagen B, Versluis M, Langedijk J, Wesselink P, van der Sluis LW. The influence of the ultrasonic intensity on the cleaning efficacy of passive ultrasonic irrigation. J Endod. 2011;37:688-92.

38- Kakehashi S, Stanley HR, Fitzgerald RJ. The Effects of Surgical Exposures of Dental Pulps in Germ-Free and Conventional Laboratory Rats. Oral Surg Oral Med Oral Pathol. 1965;20:340-9.

39- Katebzadeh N, Hupp J, Trope M. Histological periapical repair after obturation of infected root canals in dogs. J Endod. 1999;25:364-8.

40- Katebzadeh N, Sigurdsson A, Trope M. Radiographic evaluation of periapical healing after obturation of infected root canals: an in vivo study. Int Endod J. 2000;33:60-6.

41- Lee SJ, Wu MK, Wesselink PR. The effectiveness of syringe irrigation and ultrasonics to remove debris from simulated irregularities within prepared root canal walls. Int Endod J. 2004;37:672-8.

42- Leonardo MR, Almeida WA, Silva LAB, Utrilla LS. Histopathologic observations of periapical repair in teeth with radiolucent areas submitted to two different methods of root canal treatment. J Endod. 1995;21:137-41.

43- Leonardo MR, Hernandez ME, Silva LA, Tanomaru-Filho M. Effect of a calcium hydroxide-based root canal dressing on periapical repair in dogs: a histological study. Oral Surg Oral Med Oral Pathol Oral Radiol Endod. 2006 Nov;102(5):680-5. 
44- Leonardo MR, Rossi MA, Silva LA, Ito IY, Bonifácio KC. EM evaluation of bacterial biofilm and microorganisms on the apical external root surface of human teeth. J Endod. 2002 Dec;28(12):815-8.

45- Leonardo MR, Salgado AA, da Silva LA, Tanomaru Filho M. Apical and periapical repair of dogs' teeth with periapical lesions after endodontic treatment with different root canal sealers. Pesqui Odontol Bras. 2003 Jan-Mar;17(1):69-74.

46- Leonardo MR, Silva LA, Leonardo RT, Utrilla LS, Assed S. Histological evaluation of therapy using a calcium hydroxide dressing for teeth with incompletely formed apices and periapical lesions. J Endod. 1993;19:348-52.

47- Leonardo MR. Endodontia: tratamento de canais radiculares. São Paulo: Artes Médicas; 2005.

48- Love RM, Jenkinson HF. Invasion of dentinal tubules by oral bacteria. Crit Rev Oral Biol Med. 2002;13(2):171-83.

49- Malentacca A, Uccioli U, Zangari D, Lajolo C, Fabiani C. Efficacy and safety of various active irrigation devices when used with either positive or negative pressure: an in vitro study. J Endod. 2012 Dec;38(12):1622-6.

50- Meder-Cowherd L, Williamson AE, Johnson WT, Vasilescu D, Walton R, Qian F. Apical morphology of the palatal roots of maxillary molars by using micro-computed tomography. J Endod. 2011 Aug;37(8):1162-5.

51- Mehdipour O, Kleier DJ, Averbach RE. Anatomy of sodium hypochlorite accidents. Compend Contin Educ Dent. 2007;28:544-6.

52- Metzler RS, Montgomery S. Effectiveness of ultrasonics and calcium hydroxide for the debridement of human mandibular molars. J Endod. 1989;15:373-8.

53- Mitchell RP, Baumgartner JC, Sedgley CM. Apical extrusion of sodium hypochlorite using different root canal irrigation systems. J Endod. 2011;37:1677-81.

54- Moller AJ, Fabricius L, Dahlen G, Ohman AE, Heyden G. Influence on periapical tissues of indigenous oral bacteria and necrotic pulp tissue in monkeys. Scand J Dent Res. $1981 ; 89: 475-84$.

55- Morfis A, Sylaras SN, Georgopoulou M, Kernani M, Prountzos F. Study of the apices of human permanent teeth with the use of a scanning electron microscope. Oral Surg Oral Med Oral Pathol. 1994;77:172-6.

56- Morroquin BB, El-Sayed MAA, Willershausen-Zonnchen B. Morphology of the physiological foramen: I-maxillary and mandibular molars. J Endod. 2004;30:321-8.

57- Mozo S, Llena C, Forner L. Review of ultrasonic irrigation in endodontics: increasing action of irrigating solutions. Med Oral Patol Oral Cir Bucal. 2012 May 1;17(3):e512-6.

58- Munley PJ, Goodell GG. Comparison of passive ultrasonic debridement between fluted and nonfluted instruments in root canals. J Endod. 2007;33:578-80.

59- Munoz HR, Camacho-Cuadra K. In vivo efficacy of three different endodontic irrigation systems for irrigant delivery to working length of mesial canals of mandibular molars. $J$ Endod. 2012 Apr;38(4):445-8. 
60- Nair PN, Henry S, Cano V, Vera J. Microbial status of apical root canal system of human mandibular first molars with primary apical periodontitis after "one-visit" endodontic treatment. Oral Surg Oral Med Oral Pathol Oral Radiol Endod 2005; 99: 231-252.

61-Naito T. Single or multiple visits for endodontic treatment? Evid Based Dent. 2008;9(1):24.

62- Ng YL, Mann V, Rahbaran S, Lewsey J, Gulabivala K. Outcome of primary root canal treatment: systematic review of the literature - part 1. Effects of study characteristics on probability of success. Int Endod J. 2007;40:921-39.

63- Nielsen BA, Baumgartner J. Comparison of the EndoVac system to needle irrigation of root canals. J Endod. 2007;33:611-5.

64- Paiva SS, Siqueira JF Jr, Rôças IN, Carmo FL, Leite DC, Ferreira DC, Rachid CT, Rosado AS. Molecular microbiological evaluation of passive ultrasonic activation as a supplementary disinfecting step: a clinical study. J Endod. 2013 Feb;39:190-4.

65- Panzarini SR, Souza V, Holland R, Dezan Júnior E. Association of calcium hydroxide and metronidazole in the treatment of dog's teeth with chronic periapical lesion. J Appl Oral Sci. 2006 Oct;14(5):334-40.

66- Paredes-Vieyra J, Enriquez FJ. Success rate of single- versus two-visit root canal treatment of teeth with apical periodontitis: a randomized controlled trial. J Endod. 2012 Sep;38(9):1164-9.

67- Parente JM, Loushine RJ, Susin L, Gu L, Looney SW, Weller RN, Pashley DH, Tay FR. Root canal debridement using manual dynamic agitation or the EndoVac for final irrigation in a closed system and an open system. Int Endod J. 2010 Nov;43(11):1001-12.

68- Paula-Silva FW, Santamaria M Jr, Leonardo MR, Consolaro A, da Silva LA. Cone-beam computerized tomographic, radiographic, and histologic evaluation of periapical repair in dogs' post-endodontic treatment. Oral Surg Oral Med Oral Pathol Oral Radiol Endod. 2009;108:796-805.

69- Peters LB, van Winkelhoff AJ, Buijs JF, Wesselink PR. Effects of instrumentation, irrigation and dressing with calcium hydroxide on infection in pulpless teeth with periapical bone lesions. Int Endod J 2002; 35: 13-21.

70- Prashanth MB, Tavane PN, Abraham S, Chacko L. Comparative evaluation of pain, tenderness and swelling followed by radiographic evaluation of periapical changes at various intervals of time following single and multiple visit endodontic therapy: an in vivo study. J Contemp Dent Pract. 2011 May 1;12(3):187-91.

71- Ribeiro EM, Silva-Sousa YT, Souza-Gabriel AE, Sousa-Neto MD, Lorencetti KT, Silva SR. Debris and smear removal in flattened root canals after use of different irrigant agitation protocols. Microsc Res Tech. 2012 Jun;75(6):781-90.

72- Richman MJ. The use of ultrasonics in root canal therapy and root resection. J Dent Med. 1957;12:12-8.

73- Rôças IN, Siqueira JF Jr. Characterization of microbiota of root canal-treated teeth with posttreatment disease. J Clin Microbiol. 2012 May;50(5):1721-4. 
74- Rocha CT, Rossi MA, Leonardo MR, Rocha LB, Nelson-Filho P, Silva LA. Biofilm on the apical region of roots in primary teeth with vital and necrotic pulps with or without radiographically evident apical pathosis. Int Endod J. 2008 Aug;41(8):664-9.

75- Sabeti MA, Nekofar M, Motahhary P, Ghandi M, Simon JH. Healing of apical periodontitis after endodontic treatment with and without obturation in dogs. J Endod. 2006 Jul;32(7):628-33.

76- Sabins RA, Johnson JD, Hellstein JW. A comparison of the cleaning efficacy of shortterm sonic and ultrasonic passive irrigation after hand instrumentation in molar root canals. J Endod. 2003 Oct;29(10):674-8.

77- Sathorn C, Parashos $\mathrm{P}$, Messer H. The prevalence of postoperative pain and flare-up in single- and multiple-visit endodontic treatment: a systematic review. Int Endod J. 2008 Feb;41(2):91-9.

78- Sathorn C, Parashos P, Messer HH. Effectiveness of single- versus multiple-visit endodontic treatment of teeth with apical periodontitis: a systematic review and metaanalysis. Int Endod J. 2005 Jun;38(6):347-55.

79- Schilder H. Cleaning and shaping the root canal. Dent Clin North Am. 1974;18:269-96.

80- Shekhar V, Shashikala K. Cone beam computed tomography evaluation of the periapical status of nonvital tooth with open apex obturated with mineral trioxide aggregate: a case report. Case Rep Dent. 2013;2013:714585.

81- Shin SJ, Kim HK, Jung IY, Lee CY, Lee SJ, Kim E. Comparison of the cleaning efficacy of a new apical negative pressure irrigating system with conventional irrigation needles in the root canals. Oral Surg Oral Med Oral Pathol Oral Radiol Endod. 2010;109:479-84.

82- Silva LA, da Silva RA, Branco LG, Navarro VP, Nelson-Filho P. Quantitative radiographic evaluation of periapical bone resorption in dog's teeth contaminated with bacterial endotoxin (LPS) associated or not with calcium hydroxide. Braz Dent J. 2008;19(4):296-300.

83- Silva LAB, Nelson-Filho P, Silva RAB, Flores DS, Heilborn C, Johnson JD, Cohenca N. Revascularization and periapical repair after endodontic treatment using apical negative pressure irrigation versus conventional irrigation plus triantibiotic intracanal dressing in dogs' teeth with apical periodontitis. Oral Surg Oral Med Oral Pathol Oral Radiol Endod. 2010;109:779-87.

84- Silva RA, Ferreira PD, De Rossi A, Nelson-Filho P, Silva LA. Toll-like receptor 2 knockout mice showed increased periapical lesion size and osteoclast number. J Endod. 2012 Jun;38(6):803-13.

85- Silveira AM, Lopes HP, Siqueira JF Jr, Macedo SB, Consolaro A. Periradicular repair after two-visit endodontic treatment using two different intracanal medications compared to single-visit endodontic treatment. Braz Dent J. 2007;18(4):299-304.

86- Siqueira JF Jr, Rôças IN, Paiva SS, Guimarães-Pinto T, Magalhães KM, Lima KC. Bacteriologic investigation of the effects of sodium hypochlorite and chlorhexidine during the endodontic treatment of teeth with apical periodontitis. Oral Surg Oral Med Oral Pathol Oral Radiol Endod. 2007 Jul;104(1):122-30. 
87- Siqueira JF, Rôças IN, Alves FR, Santos KR. Selected endodontic pathogens in the apical third of infected root canals: a molecular investigation. J Endod. 2004;30:638-43.

88- Siu C, Baumgartner JC. Comparison of the debridement efficacy of the EndoVac irrigation system and conventional needle root canal irrigation in vivo. $J$ Endod. 2010;36:1782-5.

89- Sjogren U, Figdor D, Persson S, Sundqvist G. Influence of infection at the time of root filling on the outcome of endodontic treatment of teeth with apical periodontitis. Int Endod J. 1997;30:297-306.

90- Spoleti P, Siragusa M, Spoleti MJ. Bacteriological evaluation of passive ultrasonic activation. J Endod. 2003;29:12-4.

91- Spoorthy E, Velmurugan N, Ballal S, Nandini S. Comparison of irrigant penetration up to working length and into simulated lateral canals using various irrigating techniques. Int Endod J. 2013 Jan 16. doi: 10.1111/iej.12065. [Epub ahead of print]

92- Tanomaru Filho M, Leonardo MR, Silva LAB. Effect of irrigating solution and calcium hydroxide root canal dressing on the repair of apical and periapical tissues of teeth with periapical lesion. J Endod. 2002;28:295-9.

93- Tay FR, Gu LS, Schoeffel GJ, Wimmer C, Susin L, Zhang K, Arun SN, Kim J, Looney SW, Pashley $\mathrm{DH}$. Effect of vapor lock on root canal debridement by using a side-vented needle for positive-pressure irrigant delivery. J Endod. 2010;36:745-50.

94- Taylor RD. Modification of the Brown and Brenn gram stain for the differential staining of gram-positive and gram-negative bacteria in tissue sections. Am J Clin Pathol. 1966 Oct;46(4):472-4.

95- Teixeira RC, Rubira CM, Assis GF, Lauris JR, Cestari TM, Rubira-Bullen IR. Radiological and histopathological evaluation of experimentally-induced periapical lesion in rats. $\mathrm{J}$ Appl Oral Sci. 2011 Oct;19(5):500-4.

96- Tronstad L, Barnett F, Riso K, Slots J. Extraradicular endodontic infections. Endod Dent Traumatol. 1987;3:86-90.

97- Trope M, Delano EO, Orstavik D. Endodontic treatment of teeth with apical periodontitis: single vs. multivisit treatment. J Endod. 1999;25:345-50.

98- Van der Sluis LW, Versluis M, Wu MK, Wesselink PR. Passive ultrasonic irrigation of the root canal: a review of the literature. Int Endod J. 2007;40:415-26.

99- Van der Sluis LW, Wu MK, Wesselink PR. The efficacy of ultrasonic irrigation to remove artificially placed dentine debris from human root canals prepared using instruments of varying taper. Int Endod J. 2005;38:764-8.

100-Vera J, Siqueira JF Jr, Ricucci D, Loghin S, Fernández N, Flores B, Cruz AG. Oneversus two-visit endodontic treatment of teeth with apical periodontitis: a histobacteriologic study. J Endod. 2012 Aug;38(8):1040-52.

101-Walmsley AD. Ultrasound and root canal treatment: the need for scientific evaluation. Int Endod J. 1987 May;20(3):105-11. 
102-Walsh MC, Kim N, Kadono Y, Rho J, Lee SY, Lorenzo J, Choi Y. Osteoimmunology: interplay between the immune system and bone metabolism. Annu Rev Immunol. 2006;24:33-63.

103-Wang J, Jiang Y, Chen W, Zhu C, Liang J. Bacterial flora and extraradicular biofilm associated with the apical segment of teeth with post-treatment apical periodontitis. $J$ Endod. 2012 Jul;38(7):954-9.

104-Weller RN, Brady JM, Bernier WE. Efficacy of ultrasonic cleaning. J Endod. 1980 Sep;6(9):740-3. 
Anexo 



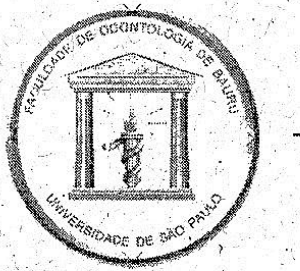

\section{Universidade de São Paulo Faculdade de Odontologia de Bauru}

Comissão de Ética no Ensino e Pesquisa em Animais

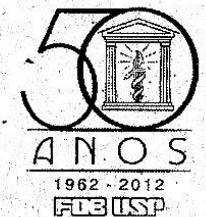

CEEPA-PROC. $\mathrm{N}^{\circ} 014 / 2012$

Bauru, 7 de agosto de 2012.

Senhora Professora,

Informamos que após o envio da documentação solicitada, o projeto de pesquisa encaminhado a este comitê de Ética em Pesquisa em Seres Humanos, denominado Irrigação por pressão negativa (EndoVac) versus sistema de irrigação ultrassônica Estudo microbiológico, histopátológico, imunohistoquímico e histoenzimológico, em dentes de cães com lesão periapical, de sua áutoria e dos Profs. Drs. Paulo Nelson-Filho, Raquel Assed Bezerra da Silva e Nestor Cohenca, foi novamente enviado ao relator para avaliação e considerado APROVADO "ad referendum" desta Comissão, nesta data.

Solicitamos que ao final da pesquisa seja enviado, para avaliação desta Comissão, um Relatório com os resultados obtidos para análise ética e emissão de parecer final, o qual poderả ser utilizado para fins de publicação científica.

Atenciosamiente,

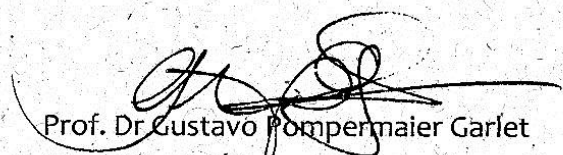

Presidente da Comissão de Ética no Ensino e Pesquisa em Animais

Prof ${ }^{\mathrm{D}} \mathrm{r}^{\mathrm{a}}$ Léa Assed Bezerra da Silva,

Docente do Departamento de Clínica Infantil, Odontologia Preventiva e Social

Al. Dr. Octávio Pinheiro Brisolla, 9-75 - Bauru-SP - CEP 17012-101 - C.P. 73

e-mail: mferrari@fob.usp.br - Fone/FAX (0xx14) 3235-8356

http://www fob.usp.br 